Vitor C. Coletta, Renato V. Gonçalves, Maria I. B. Bernardi, Dorian A. H. Hanaor, M. Hussein N. Assadi, Francielle C. F. Marcos, Francisco G. E. Nogueira, Elisabete M. Assaf, Valmor R. Mastelaro

\title{
Cu-modified SrTiO3 perovskites toward enhanced water-gas shift catalysis: A combined experimental and computational study
}

Journal article | Accepted manuscript (Postprint)

This version is available at https://doi.org/10.14279/depositonce-11726

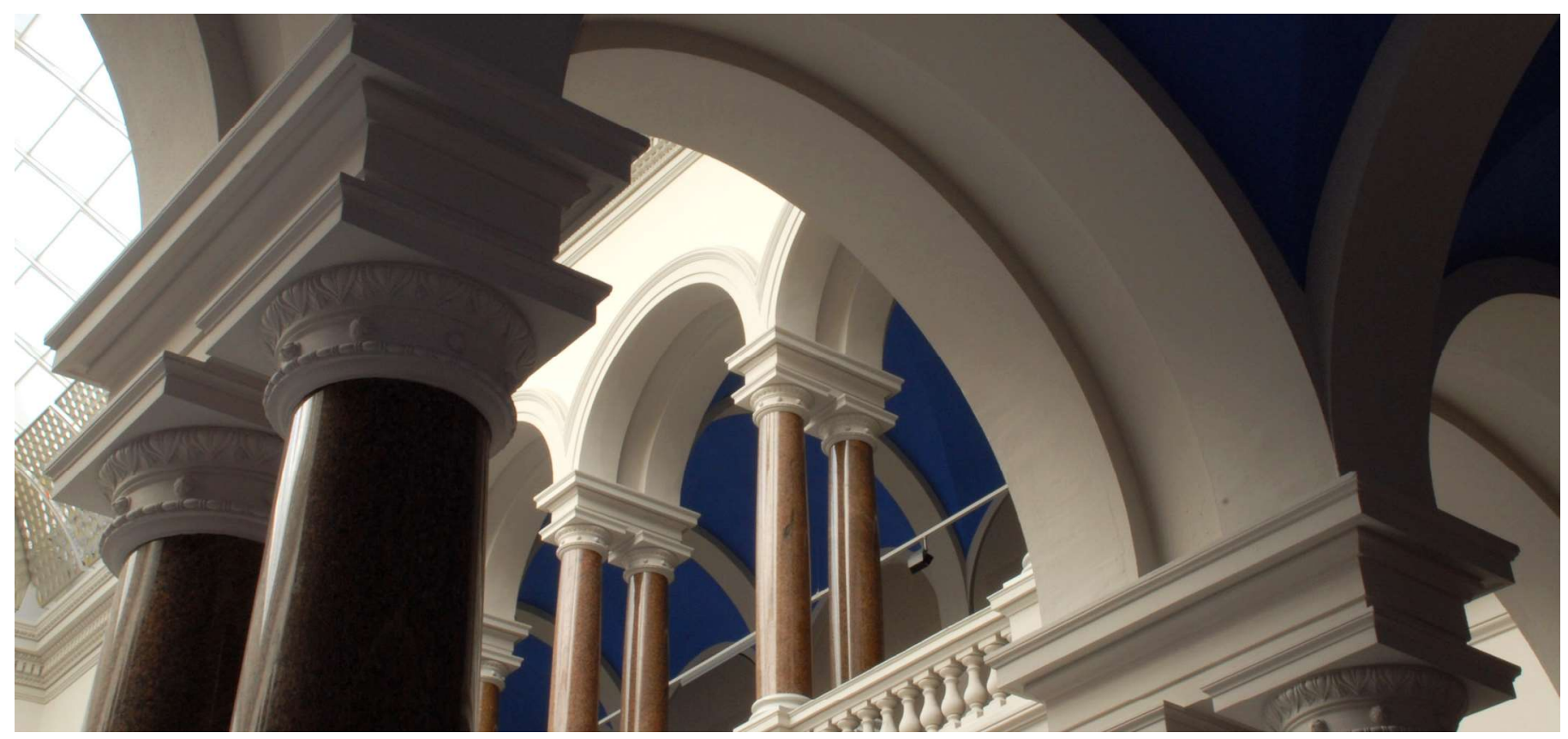

Coletta, V. C., Gonçalves, R. V., Bernardi, M. I. B., Hanaor, D. A. H., Assadi, M. H. N., Marcos, F. C. F., Nogueira, F. G. E., Assaf, E. M., \& Mastelaro, V. R. (2020). Cu-Modified SrTiO3 Perovskites Toward Enhanced Water-Gas Shift Catalysis: A Combined Experimental and Computational Study. ACS Applied Energy Materials, 4(1), 452-461. https://doi.org/10.1021/acsaem.0c02371

This document is the Accepted Manuscript version of a Published Work that appeared in final form in ACS Applied Energy Materials, copyright (c) American Chemical Society after peer review and technical editing by the publisher. To access the final edited and published work see https://doi.org/10.1021/acsaem.0c02371. 


\title{
Cu-Modified $\mathrm{SrTiO}_{3}$ Perovskites Toward Enhanced Water-Gas Shift Catalysis: A Combined Experimental and Computational Study
}

Vitor C. Coletta ${ }^{\mathrm{a}}$, Renato V. Gonçalves ${ }^{\mathrm{a}}$, Maria I. B. Bernardi ${ }^{\mathrm{a}}$, Dorian A. H. Hanaor ${ }^{\mathrm{b}}$, M. Hussein. N. Assadic, Francielle C. F. Marcos ${ }^{\mathrm{d}}$, Francisco G. E. Nogueira ${ }^{\mathrm{e}}$, Elisabete M. Assaf $^{f}$, Valmor R. Mastelaro, ${ }^{\mathrm{a}, *}$

a São Carlos Institute of Physics, University of São Paulo, SP, 13566-590, São Carlos, SP, Brazil.

${ }^{\mathrm{b}}$ Chair of Advanced Ceramic Materials, Technische Universität Berlin, 10623, Germany.

${ }^{\mathrm{c}}$ Center for Green Research on Energy and Environmental Materials, National Institute for Materials Science (NIMS), Tsukuba 305-0044, Japan.

${ }^{d}$ Polytechnic School of the University of São Paulo, 05508-010, Department of Chemical Engineering, University of São Paulo, 05508-010, São Paulo, SP, Brazil.

${ }^{\mathrm{e}}$ Department of Chemical Engineering, Federal University of São Carlos, 13565-905, São Carlos, SP, Brazil.

${ }^{\mathrm{f}}$ São Carlos Institute of Chemistry, University of São Paulo, 13560-970, São Carlos, SP, Brazil.

*Corresponding author, email: valmor@ifsc.usp.br

\begin{abstract}
:
The water-gas shift reaction (WGS) is important and widely applied in the production of $\mathrm{H}_{2}$. Cu-modified perovskites are promising catalysts for WGS reactions in hydrogen generation. However, the structure-dependent stability and reaction pathways of such materials remain unclear. Herein, we report catalytically active $\mathrm{Cu}$-modified $\mathrm{SrTiO}_{3}$ (nominally $\mathrm{SrTi}_{1-x} \mathrm{Cu}_{x} \mathrm{O}_{3}$ ) prepared by a modified polymeric precursor method. Microstructural analysis revealed a partially segregated $\mathrm{CuO}$ phase in the as-prepared materials. Operando X-ray diffraction and absorption spectroscopy showed the reduction of $\mathrm{CuO}$ into a stable metallic phase under conditions of WGS reactions for all compositions. Among the characterized materials, the $x=0.20$ composition showed the highest turnover frequency, lowest activation energy, and the highest WGS rate at $300{ }^{\circ} \mathrm{C}$. According to density functional calculations, the formation of $\mathrm{CuO}$ is energetically less favorable compared with, $\mathrm{SrTiO}_{3}$, explaining why the segregated $\mathrm{CuO}$ phase on the $\mathrm{SrTiO}_{3}$ surface is reduced to $\mathrm{Cu}$ during the catalytic reaction, while $\mathrm{SrTiO}_{3}$ remains. For $x=0.20$, the size of the segregated $\mathrm{CuO}$ phase is optimum for facilitating the catalytic reaction. In contrast, a higher $\mathrm{Cu}$ content $(x=0.3)$ results in an aggregation of smaller $\mathrm{CuO}$ particles, resulting in fewer surface active sites and a net decrease in catalytic performance.
\end{abstract}

KEYWORDS: water-gas shift, $\mathrm{SrTiO}_{3}$, DFT calculations, perovskite catalysts, operando XAS, XRD, $\mathrm{Cu}$ doping, $\mathrm{CuO}$ formation 


\section{INTRODUCTION}

Currently, the most widely employed method for hydrogen production is methane steam reforming, which generates $\mathrm{CO}$ as a byproduct. ${ }^{1}$ In addition to being a harmful gas, carbon monoxide is particularly undesirable for the application of hydrogen fuel in proton exchange membrane fuel cells (PEMFCs), which stand out due to their robustness and versatility but generally employ platinum electrodes, which are contaminated if exposed to $\mathrm{CO}^{2}{ }^{2}$ To eliminate $\mathrm{CO}$ from product gases, the output of methane steam reforming processes generally requires further treatment, which is most often achieved through the water-gas shift (WGS) reaction $\left(\mathrm{CO}+\mathrm{H}_{2} \mathrm{O} \rightarrow\right.$ $\mathrm{CO}_{2}+\mathrm{H}_{2}$ ) followed by the preferential oxidation (PROX) of $\mathrm{CO}\left(2 \mathrm{CO}+\mathrm{O}_{2} \rightarrow 2 \mathrm{CO}_{2}\right)$ to minimize its concentration and provide further hydrogen output. ${ }^{1-4}$ To achieve acceptable conversion rates and reaction kinetics, the WGS reaction is generally carried out in high- and low-temperature stages. In contemporary usage, $\mathrm{Fe}_{2} \mathrm{O}_{3}-\mathrm{Cr}_{2} \mathrm{O}_{3}$ and $\mathrm{Cu} / \mathrm{ZnO}-\mathrm{Al}_{2} \mathrm{O}_{3}$ systems are applied commercially as WGS catalysts for high- and low-temperature reactions, respectively. ${ }^{1-4}$

Alternative copper-loaded catalysts have been proposed for the WGS reaction, notably spinels ${ }^{5-9}$ and rare earth oxides. ${ }^{10-19}$ Perovskite oxides with $\mathrm{ABO}_{3}$ structures have, in recent years, drawn increasing interest in various catalytic reactions due to their low cost, high stability, and diverse cationic substitutions that can be accommodated in their structure. ${ }^{20-28}$ Perovskite strontium titanate $\left(\mathrm{SrTiO}_{3}\right)$, in a metal-oxide solidsolution or pristine form as support of metal oxides, has been applied in various studies of catalytic reactions such as propane oxidation, ${ }^{20}$ methanol decomposition, ${ }^{21}$ dry reforming of methane, ${ }^{22} \mathrm{NO}_{\mathrm{x}}$ reduction, ${ }^{23}$ soot combustion, ${ }^{24} \mathrm{CO}$ oxidation, ${ }^{25,26}$ NO reduction, ${ }^{27}$ and oxidative coupling of methane. ${ }^{28} \mathrm{SrTiO}_{3}$ based materials remain ripe for further exploration towards new catalysts for water-gas shift (WGS) applications.

Studies into $\mathrm{SrTiO}_{3}$ systems containing copper often show that catalytic properties are improved when copper exists as a segregated $\mathrm{CuO}$ phase, with the $\mathrm{SrTiO}_{3}$ phase generally acting as a support and $\mathrm{CuO}$ as the active phase in many of these catalytic processes. ${ }^{23-25,27}$ These studies also show the importance of interactions between the $\mathrm{SrTiO}_{3}$ and $\mathrm{CuO}$ phases in relation to catalyst properties. In the case of $\mathrm{SrTi}_{1-x} \mathrm{Cu}_{x} \mathrm{O}_{3}$ solid solutions, low catalytic activity is generally observed, as copper atoms were only embedded within the structure of the $\mathrm{SrTiO}_{3}$ phase, while in contrast, the presence of $\mathrm{Cu}$ in metallic or oxide forms at the surface of $\mathrm{SrTiO}_{3}$ promotes various catalytic reactions. ${ }^{23-25,27}$

In a previous investigation, we reported the synthesis and structural characterization of $\mathrm{SrTi}_{1-x} \mathrm{Cu}_{x} \mathrm{O}_{3}(x=0.03$ $0.15){ }^{29}$ It was shown that nominally substitutional copper in the samples segregates apart from the perovskite structure for $x \geq 0.06$ in the form of a secondary $\mathrm{CuO}$ phase, which can be reduced to metallic copper at temperatures of $\sim 300{ }^{\circ} \mathrm{C}$ in a hydrogen atmosphere. Based on these results, we predict that these materials, mainly for the compositions showing $\mathrm{CuO}$ segregation, may exhibit useful catalytic functionality. The attributes of the $\mathrm{SrTiO}_{3}$ compound containing $\mathrm{Cu}$ atoms concerning different catalysis reactions described previously motivate the further study of this system for WGS applications.

Thus, in the present study, we determined the compositionally dependent efficacy of $\mathrm{SrTi}_{1-x} \mathrm{Cu}_{x} \mathrm{O}_{3}$ systems toward the WGS reaction, considering the compositions where segregation of the $\mathrm{CuO}$ phase was previously observed. ${ }^{29}$ The short- and longrange-order structure, as well as the electronic structure of the catalysts under operando 
conditions, and the catalytic performance toward the WGS reaction were characterized. A fundamental DFT study was conducted to examine the behavior of the studied materials from first principles to elucidate the aggregation tendencies of $\mathrm{Cu}$ atoms both within the host lattice and on the surface of $\mathrm{SrTiO}_{3}$, which eventually leads to the segregation of the $\mathrm{CuO}$ phase.

\section{EXPERIMENTAL AND COMPUTATIONAL SETTINGS}

Catalyst Synthesis. $\mathrm{Cu}$-modified $\mathrm{SrTiO}_{3}$ nanoparticles were synthesized by a polymeric precursor method (Pechini synthesis), a variant of sol-gel processing that facilitates homogenous cation dispersion through steric entrapment. A more detailed description of such synthesis has been published elsewhere. ${ }^{29,30}$ In this synthesis, $\mathrm{SrTi}_{1-x} \mathrm{Cu}_{x} \mathrm{O}_{3}$ with $x=0.15,0.20$ and 0.30 was prepared using $\mathrm{Sr}\left(\mathrm{NO}_{3}\right)_{2}$, $\operatorname{Ti}\left[\mathrm{OCH}\left(\mathrm{CH}_{3}\right)_{2}\right]_{4}$ and $\mathrm{Cu}\left(\mathrm{NO}_{3}\right)_{2} .3 \mathrm{H}_{2} \mathrm{O}$ as precursors in stoichiometric amounts. Cation chelation was achieved by the addition of citric acid in distilled water with a citric acid:cation molar ratio of $4: 1 .^{29}$ The citrate chelated solutions were prepared separately for $\mathrm{Sr}, \mathrm{Cu}$, and $\mathrm{Ti}$, and the precursor resins were produced by mixing citrate solutions in appropriate quantities and subsequent esterification by the addition of ethylene glycol (EG) with an EG/citric acid mass ratio of $2: 3$ and evaporation of water under heated stirring. The obtained resins were dried in air at $300{ }^{\circ} \mathrm{C}$ for $8 \mathrm{~h}$ to obtain precursor powders, which were then heat-treated under $\mathrm{N}_{2}$ flux at $750{ }^{\circ} \mathrm{C}$ for $2 \mathrm{~h}$. Samples were further treated with 330 $\mathrm{mL} / \mathrm{min}$ of oxygen flux at $500{ }^{\circ} \mathrm{C}$ for $2 \mathrm{~h}$ with a heating rate of $10^{\circ} \mathrm{C} \mathrm{min}^{-1}$.

Electron Microscopy. Scanning transmission electron microscopy (STEM) of the studied samples was performed with an FEI Tecnai $\mathrm{G}^{2}$ F20 microscope operated at $200 \mathrm{kV}$ with a high angle annular dark-field (HAADF) detector. By using this apparatus, EDX mapping images were acquired with an EDAX DX-4 system. For this analysis, particles were dispersed ultrasonically in isopropyl alcohol and deposited on $\mathrm{Ni}$ grids.

X-ray diffraction (XRD). Conventional exsitu XRD patterns of materials at ambient temperature were recorded using a Rigaku Ultima IV diffractometer with $\mathrm{Cu} \mathrm{K} \alpha$ radiation $(\lambda=1.54 \AA)$ at $2 \theta=20^{\circ}-100^{\circ}$ with a $0.02^{\circ}$ step size and 3 s per step. Rietveld refinement procedures were carried out using GSAS software. ${ }^{31}$ For these refinements, crystallographic information files of $\mathrm{SrTiO}_{3}$ (CIF-80873), $\mathrm{CuO}$ (CIF-16025), and $\mathrm{SrCO}_{3}$ (CIF-15195) were used as reference structures.

Operando X-ray diffraction
measurements were conducted during representative WGS reactions at the XPD beamline of the National Laboratory of Synchrotron Light (LNLS, Campinas - Brazil, proposal number 17001) using a Huber diffractometer, Arara furnace, and Mythen detector. XRD patterns were collected over the $2 \theta$ range 35 to $45^{\circ}$, with radiation of $\lambda=$ $1.5498 \AA$ using a Si (111) monochromator. Diffraction measurements were performed for samples that had previously been reduced at $250{ }^{\circ} \mathrm{C}$ under a $5 \%$ vol. $\mathrm{H}_{2} / \mathrm{He}$ atmosphere for $30 \mathrm{~min}$. After the reduction, the furnace was purged with inert gas, and the temperature was raised to $350{ }^{\circ} \mathrm{C}$. For the investigative WGS measurements and operando XRD, the gas mixture was fixed at $5 \mathrm{vol} \%$. CO/He at a flux rate of $60 \mathrm{~mL} / \mathrm{min}$, and water was supplied by a saturator at a molar ratio $\mathrm{CO}: \mathrm{H}_{2} \mathrm{O}$ equal to $1: 3$. The feed composition of $5 \mathrm{vol} \% \mathrm{CO} / \mathrm{He}$ was supplied by Brooks Instrument mass flow controllers, while the flow control of He that fed the saturator with water was controlled through a rotameter. The temperature of the saturator was kept at $298 \mathrm{~K}$ during the experiment to keep constant the molar ratio $\mathrm{CO}: \mathrm{H}_{2} \mathrm{O}$ equal to $1: 3$. The temperature of the saturator was measured with $\mathrm{K}$ type thermocouple. Besides that, the temperature 
of the line from the saturator to the reactor was maintained heating.

X-ray Absorption Spectroscopy (XAS). Xray absorption near-edge spectroscopy (XANES) was performed in operando at the $\mathrm{Cu}$ K-edge $(8979 \mathrm{eV})$ in the XAFS2 synchrotron beamline at LNLS (LNLS, Campinas - Brazil, proposal number 18857). Powders were blended with boron nitride and compacted into pellets, which were placed under the normal incidence of the X-ray beam. The parameters for spectral recording and treatment are as previously reported. ${ }^{29}$ Similar to operando XRD experiments, the samples were reduced, and XANES spectra were collected during the WGS reaction at $350{ }^{\circ} \mathrm{C}$ using a gas mixture of $5 \mathrm{vol} \%$. A saturator supplied $\mathrm{CO} / \mathrm{He}$ at a flow rate of $60 \mathrm{~mL} / \mathrm{min}$ and water at a molar ratio $\mathrm{CO}: \mathrm{H}_{2} \mathrm{O}$ equal to $1: 3$.

\section{Temperature-Programmed Reduction} (TPR). To evaluate the redox behavior of materials synthesized in the present work, we performed TPR measurements using a Micromeritics Chemisorb 2750 with $100 \mathrm{mg}$ of sample and a $25 \mathrm{~mL} / \mathrm{min}$ flux rate of 10 vol\%. $\mathrm{H}_{2} / \mathrm{Ar}$ gas. $\mathrm{H}_{2}$ consumption was measured using a thermal conductivity detector (TCD).

Dispersion of metallic particles. $\mathrm{N}_{2} \mathrm{O}$ chemisorption was performed to gauge the surface area and dispersion of metallic copper in reduced materials. For this analysis, $200 \mathrm{mg}$ samples were used. First, the samples were reduced by $3 \mathrm{vol} \% . \mathrm{H}_{2} / \mathrm{Ar}$ mixture at a flux of $30 \mathrm{~mL} / \mathrm{min}$ heated to $350{ }^{\circ} \mathrm{C}$ at a rate of 5 ${ }^{\circ} \mathrm{C} / \mathrm{min}$ and then cooled to $60{ }^{\circ} \mathrm{C}$ in an $\mathrm{N}_{2}$ atmosphere. Then, samples were treated in a $\mathrm{N}_{2} \mathrm{O}$ atmosphere at a flux rate of $30 \mathrm{~mL} / \mathrm{min}$ for $30 \mathrm{~min}$ for the oxidation of surface copper atoms according to the following equation:

$$
2 \mathrm{Cu}_{\text {surface }}+\mathrm{N}_{2} \mathrm{O} \rightarrow \mathrm{Cu}_{2} \mathrm{O}_{\text {surface }}+\mathrm{N}_{2} \text {. }
$$

Physically adsorbed $\mathrm{N}_{2} \mathrm{O}$ molecules were removed by $\mathrm{N}_{2}$ purging at a flow of 30 $\mathrm{mL} / \mathrm{min}$ for $1 \mathrm{~h}$. Finally, the sample underwent a second reduction with the same parameters as the first one for the calculation of hydrogen consumption required to reduce the surface copper atoms. The dispersion was calculated as the ratio between surface and total metallic copper content, obtained from the hydrogen consumption in the second and the first reduction, respectively, considering the stoichiometry of the reaction.

Catalytic activity measurements. To evaluate the catalytic performance of the materials, we performed WGS reactions using $50 \mathrm{mg}$ of fine powder samples diluted with an equal amount of quartz placed in a stainlesssteel fixed-bed tube reactor. First, the sample was treated with $\mathrm{H}_{2}$ (reducing atmosphere) at $250{ }^{\circ} \mathrm{C}$ for $1 \mathrm{~h}$. Catalytic reactions were then conducted at temperatures ranging from 200 ${ }^{\circ} \mathrm{C}$ to $300{ }^{\circ} \mathrm{C}$, with steps of $25^{\circ} \mathrm{C}$, and the total flow rate of feed was $68 \mathrm{~mL} / \mathrm{min}$ and $10 \%$ vol. $\mathrm{CO} / \mathrm{N}_{2}$ mixture, $\mathrm{H}_{2} \mathrm{O}: \mathrm{CO}=3: 1$ molar ratio. Although the stoichiometric ratio between $\mathrm{CO}$ and $\mathrm{H}_{2} \mathrm{O}$ is $1: 1$ for the WGS reaction, an excess of water is employed to prevent side reactions and thermodynamically favor the formation of the products. ${ }^{32}$ To evaluate the rate of catalyzed reactions, gaseous products were analyzed online in an Agilent 7890 A gas chromatograph equipped with two 6-port valves and a 10-port valve, TCD and FID detectors and three columns, namely, HP pona, Plot-Q, and HP molesiev. Water was condensed and removed before the analysis. All post reactor lines and valves were heated to $180{ }^{\circ} \mathrm{C}$ to prevent product condensation. The CO conversion was kept below $10 \%$. As a measure of catalytic efficiency relative to available sites, the turnover frequency (TOF) was calculated using the following expression (Equation 2):

$\operatorname{TOF}\left(s^{-1}\right)=\frac{\left(X_{C O} \times F_{C O} \times N a\right)}{\left(m_{c a t} \times S_{C u} \times n a\right)}$ 
where $X_{C O}$ represents the $\mathrm{CO}$ conversion, $F_{C O}$ is the $\mathrm{CO}$ flow $\left(\mathrm{mol} . \mathrm{s}^{-1}\right), \mathrm{Na}$ is Avogadro's number $\left(6.023 \times 10^{23} \mathrm{~atm} \cdot \mathrm{mol}^{-1}\right), m_{\text {cat }}$ is the weight of catalysts, $S_{c u}$ denotes metallic copper surface area $\left(\mathrm{m}^{2} \cdot \mathrm{g}^{-1}\right)$, and $n a$ designates the number of $\mathrm{Cu}$ atoms in a monolayer $\left(1.469 \times 10^{19}\right.$ atoms.m $\left.{ }^{-2}\right){ }^{33}$

Rates of reaction for the overall WGS reaction on $\mathrm{SrTi}_{1-x} \mathrm{Cu}_{x} \mathrm{O}_{3}$ catalysts with $x=$ $0.15,0.20$ and 0.30 at $200{ }^{\circ} \mathrm{C}$ and 1 atm total pressure were measured under differential conditions (conversion < 10\%). WGS rates were normalized by the metallic copper area

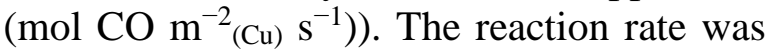
calculated using the following expression (Equation 3):

$$
\mathrm{rCO}=\frac{(\text { COin }- \text { COout })}{W \cdot S C u},
$$

where $\mathrm{rCO}$ is the inlet and outlet flow rate of $\mathrm{CO}\left(\mathrm{mol} . \mathrm{s}^{-1}\right), \mathrm{W}$ is the mass of catalyst $(\mathrm{g})$, and $\mathrm{SCu}$ is the specific surface area of metallic copper $\left(\mathrm{m}^{2} . \mathrm{g}^{-1}\right)$. An elementary reaction with first-order kinetics was assumed concerning all species in the WGS reaction, ${ }^{34}$ and the apparent activation energy (Ea) was calculated by the slope of the fitted lines. Then, the value of the slope corresponds to $E \mathrm{a} / R$, where $R$ is $8.314 \mathrm{~J} / \mathrm{mol}$. K. ${ }^{35}$

For the calculation of the equilibriumlimited CO conversion, the equilibrium constant for the WGS reaction, $\mathrm{K}_{\text {eq }}$, was obtained from Twigg's Catalyst Handbook ${ }^{36}$ and related to the concentrations of reagents and products by equation $4:^{34,37}$

$$
\mathrm{K}_{\mathrm{eq}}=\left[\mathrm{CO}_{2}\right]\left[\mathrm{H}_{2}\right] /[\mathrm{CO}]\left[\mathrm{H}_{2} \mathrm{O}\right] \text {. }
$$

Computational analysis. $\mathrm{Cu}$ formation energies in the $\mathrm{SrTiO}_{3}$ host lattice and on the surface were calculated by employing density functional theory (DFT) calculations ${ }^{38}$ within the projector augmented wave ${ }^{39-41}$ formalism as implemented in the VASP code. $^{42-43}$ Brillouin zone sampling was carried out by choosing a $7 \times 7 \times 7$ k-points set within a Monkhorst-Pack scheme that generated a grid with a spacing of $\sim 0.04 \AA^{-1}$ between k points while the energy cut-off was set to $500 \mathrm{eV}$. The total energy convergence test was performed by increasing the $\mathrm{k}$ point mesh with $\sim 0.03 \AA^{-1}$ spacing; it was found that the total energy differs only by $10^{-6} \mathrm{eV} / \mathrm{atom}$, indicating excellent convergence. We used generalized gradient approximations as parameterized by Perdew and Wang for the exchange-correlation functional. ${ }^{44}$ An orbitaldependent Hubbard term $(U)^{45}$ of the effective value of $4 \mathrm{eV}$ was applied to both $\mathrm{Ti}$ and $\mathrm{Cu}$ atoms to improve the accuracy of DFT calculations. This value of $U$ significantly improves the calculated band edge positions and defect levels in the $\mathrm{Ti}$ and $\mathrm{Cu}$ oxides. ${ }^{46-48}$ The value of $4 \mathrm{eV}$ for $\mathrm{SrTiO}_{3}$ has particularly been shown to produce an accurate band structure. ${ }^{48,49}$ Furthermore, the use of a similar $U$ value for $\mathrm{Cu}$ offers both accuracy and ease of interpretation of results. ${ }^{50}$

The formation energy $\left(E_{\mathrm{f}}\right)$ of $\mathrm{Cu}$ atoms when substituting $\mathrm{Ti}\left(\mathrm{Cu}_{\mathrm{Ti}}\right)$ or $\mathrm{Sr}\left(\mathrm{Cu}_{\mathrm{Sr}}\right)$ and when located interstitially $\left(\mathrm{Cu}_{\text {Int }}\right)$ was calculated within a $3 a \times 3 a \times 3 a$ supercell using the conventional procedure ${ }^{51,52}$ as described by the following equation:

$$
E_{\mathrm{f}}=E_{\mathrm{t}}\left(\mathrm{SrTiO}_{3}: \mathrm{Cu}\right)+\mu_{\alpha}-E_{\mathrm{t}}\left(\mathrm{SrTiO}_{3}\right)-\mu_{\mathrm{Cu}},
$$

Here, $E_{\mathrm{t}}\left(\mathrm{SrTiO}_{3}: \mathrm{Cu}\right)$ is the total energy of the $\mathrm{SrTiO}_{3}$ supercell containing the $\mathrm{Cu}$ species, and $E_{\mathrm{t}}\left(\mathrm{SrTiO}_{3}\right)$ is the total energy of the pristine $\mathrm{SrTiO}_{3}$ supercell. $\mu_{\alpha}$ and $\mu_{\mathrm{Cu}}$ are the chemical potentials of the removed ( $\mathrm{Sr}$ or $\mathrm{Ti})$ and added $(\mathrm{Cu})$ elements, respectively. $\Delta \mu$ values were set equal to the total energy of the elemental metallic phase $\left(\mu_{\text {Metal }}\right)$ plus a thermodynamically defined shift $(\Delta \mu)$. Based on thermodynamic phase stability considerations, $\Delta \mu$ can be chosen to represent either oxygen-poor or oxygen-rich environments. The detailed derivation of $\Delta \mu$ is given in the Supporting Information. To study the aggregation of a copper species in $\mathrm{SrTiO}_{3}$, 
the total energies of four configurations of a $3 a \times 3 b \times 3 c$ supercell containing two $\mathrm{Cu}$ species with varying $\mathrm{Cu}-\mathrm{Cu}$ distances $\left(d_{\mathrm{Cu}-\mathrm{Cu}}\right)$ were calculated and compared. The relative energy of these configurations $\left(E_{\mathrm{R}}\right)$ is defined as the difference in the total energy of any given configuration with the total energy of the most stable one.

\section{RESULTS AND DISCUSSION}

Structural Characterizations. Figure 1 shows the XRD patterns of the $x=0.15,0.20$ and 0.30 samples. In good agreement with our earlier work, the main crystalline phase was identified as a perovskite structure with space group $P m \overline{3} m$ with peaks corresponding to those of cubic $\mathrm{SrTiO}_{3}$ (PDF 35-0734) present alongside additional minor peaks attributed to the $\mathrm{SrCO}_{3}$ phase (PDF 5-418). As expected, the segregation of the $\mathrm{CuO}$ phase was evidenced through the main diffraction peaks of this phase located at $35.6^{\circ}$ and $38.7^{\circ} .^{29}$

Table S1 lists the lattice parameters of the perovskite phase and the fraction of the segregated $\mathrm{CuO}$ and $\mathrm{SrCO}_{3}$ phases, as

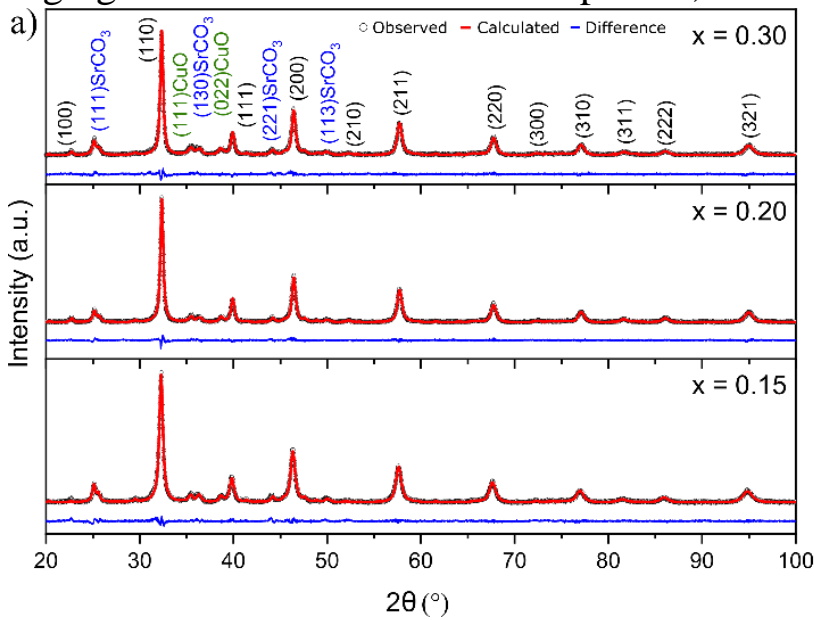

Figure 1. (a) X-ray diffraction patterns of $\mathrm{SrTi}_{1-x} \mathrm{Cu}_{x} \mathrm{O}_{3}$ and

To evaluate the copper dispersion at smaller length scales, we obtained STEM images using a HAADF detector (Figure 2). EDX mapping of $\mathrm{Cu}$ was also carried out with STEM to confirm the distribution of copperrich regions. In the $x=0.15$ sample, the copper atoms are observed to be well dispersed in the determined by Rietveld refinement. The lattice parameters for the perovskite phase in the $x=0.20$ and $x=0.30$ materials are similar and show little smaller values in comparison to the $x=0.15$ sample $(a=3.9171 \AA$ ). Considering the larger ionic radius of $\mathrm{Cu}^{2+}$ $(0.73 \AA)$ relative to $\mathrm{Ti}^{4+}(0.61 \AA)$, an expansion in the unit cell, which leads to an increasing in the lattice parameter, might be expected with the substitution of titanium by copper. On the other hand, the valence difference between $\mathrm{Cu}$ and $\mathrm{Ti}$ can bring about an energetic compensation manifesting in a shift in the position of energy bands and compensation in the unit volume, leading to a contraction of lattice parameter despite the larger size of the substituting $\mathrm{Cu}$ ion, as discussed by Janotti et al. ${ }^{53}$ The quality of the refinement is indicated by $\mathrm{R}$ and $\chi^{2}$ factors, which are close to the expected values. ${ }^{54}$ The amount of the segregated $\mathrm{CuO}$ phase was also determined (Table S1) to be equal to $5.10 \%(x$ $=0.15), 6.4 \%(x=0.20)$ and $9.2 \%(x=0.30)$. Regarding the $\mathrm{SrCO}_{3}$ phase, the $x=0.15$ and $x=0.30$ samples present around $18 \%$ while in the sample $x=0.15$, this value is only $6.5 \%$.

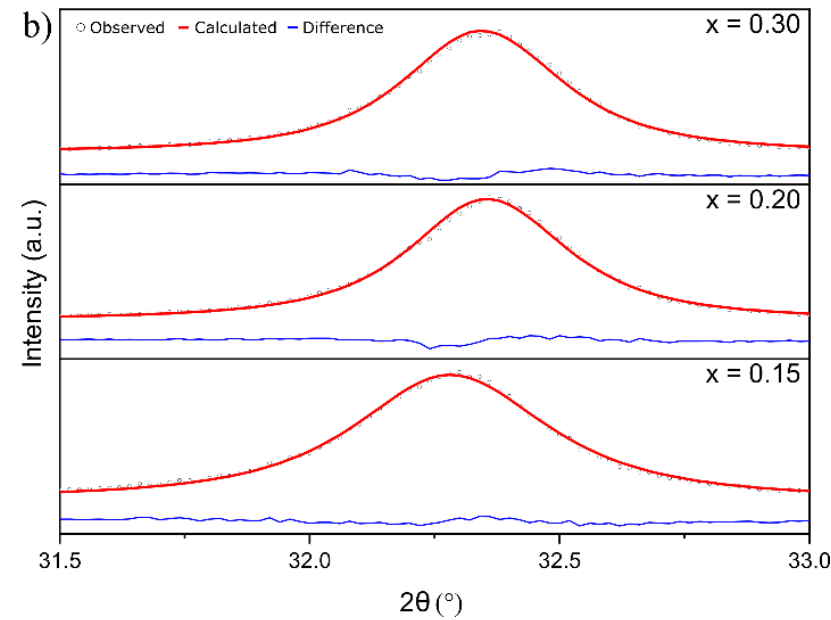

Corix and form very small particles in the $\mathrm{CuO}$ phase. In the $x=0.20$ sample, it is possible to observe the formation of some larger particles in the $\mathrm{CuO}$ phase, even more so with high dispersion, whereas in the $x=$ 0.30 sample, the aggregation of smaller $\mathrm{CuO}$ particles is observed. 


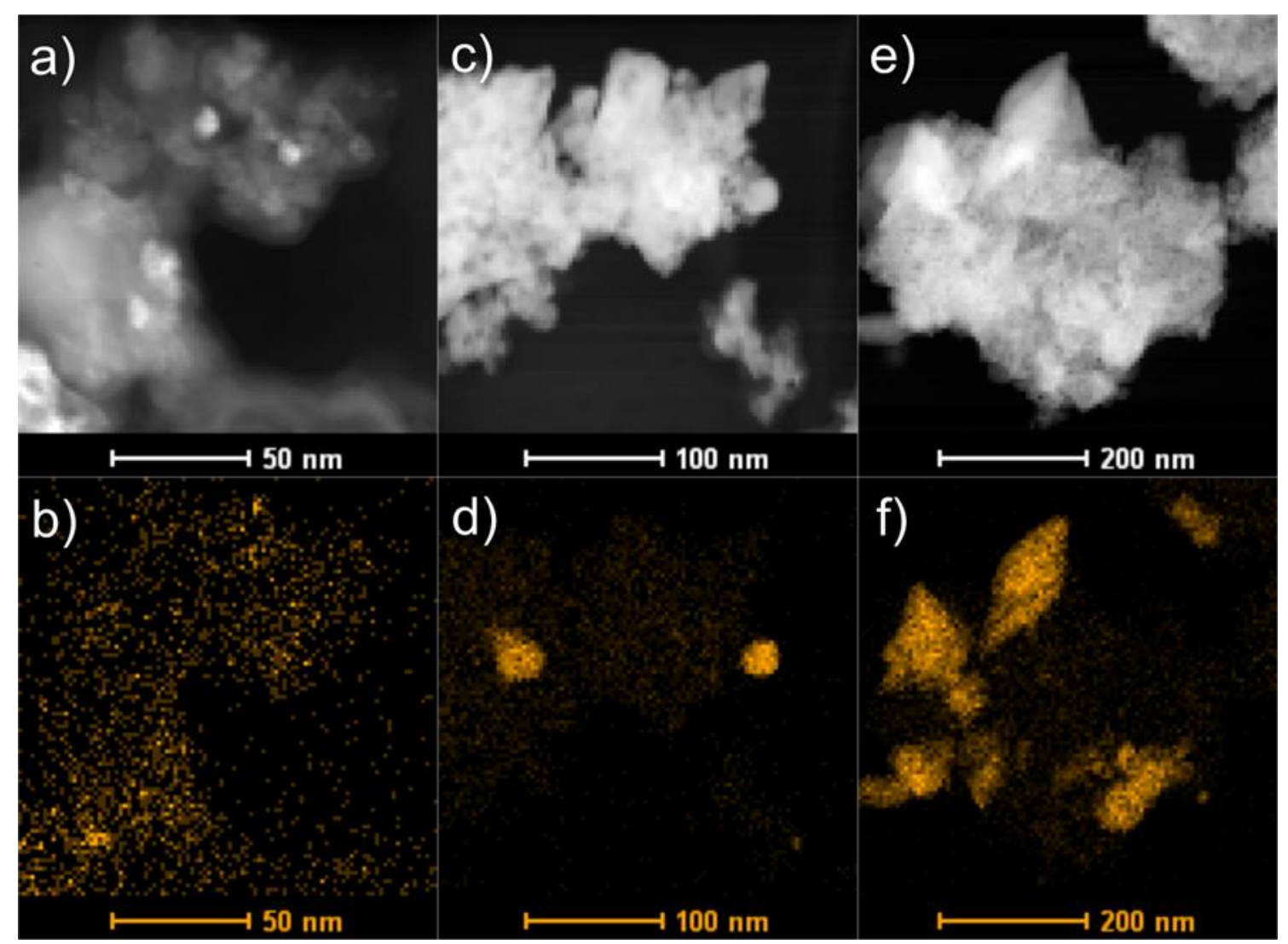

Figure 2. STEM HAADF and corresponding EDX mapping images of $\mathrm{SrTi}_{1-x} \mathrm{Cu}_{x} \mathrm{O}_{3}$ with $x=0.15(\mathrm{a}, \mathrm{b}), 0$

$.20(\mathrm{c}, \mathrm{d})$ and $0.30(\mathrm{e}, \mathrm{f})$ samples.

Additionally, we evaluated the dispersion of metallic particles on the surface of catalysts following the reduction step $\left(\mathrm{N}_{2} \mathrm{O}-\mathrm{TPD}\right)$. It was found that the dispersion of metallic copper on the surface of the perovskites decreases with increasing copper content to $11 \% \pm 1$ for $x=0.30$ catalyst compared to the $x=0.15$ and $x=0.20$ catalysts that presented dispersions of $15 \% \pm 1$ and $16 \% \pm 1$, respectively. The decrease of the dispersion of metallic copper is probably due to the increase of $\mathrm{CuO}$ particle size or aggregation of smaller $\mathrm{CuO}$ particles on the surface of the catalysts with the increasing of copper loading, as observed by STEM HAADF (Figure 2). High-resolution transmission electron microscopy (HRTEM) images (Figure 3) show atomic planes separated at distances of approximately 0.24 $\mathrm{nm}$, corresponding to the (111) plane of the $\mathrm{CuO}$ phase (PDF 48-1548).

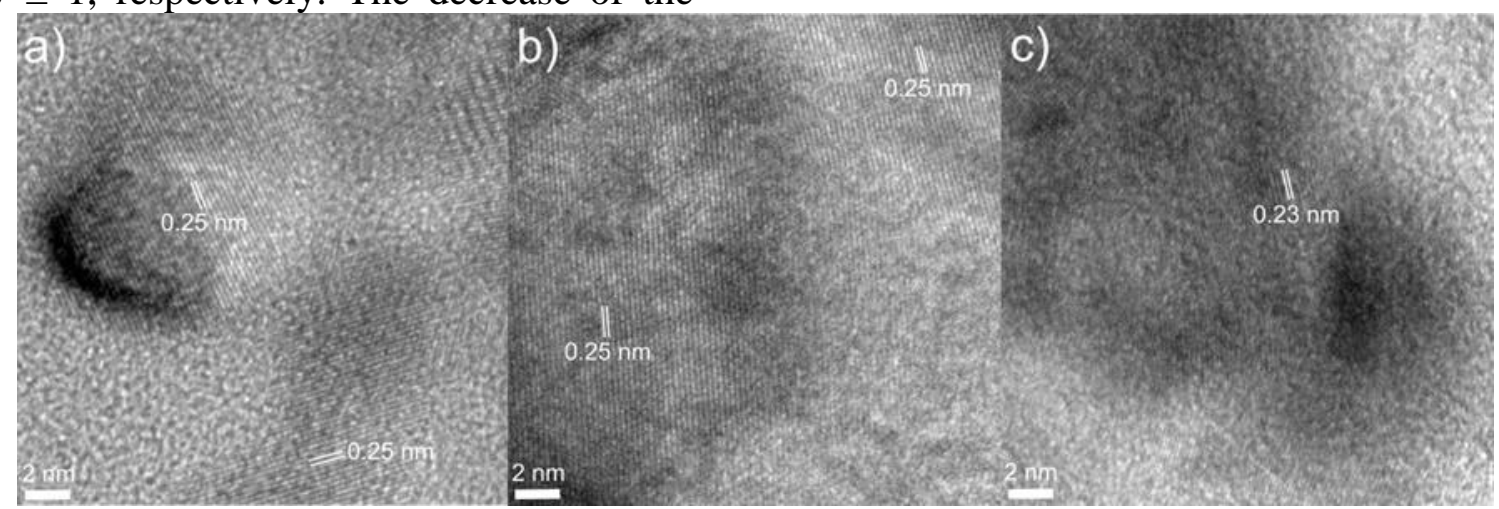

Figure 3. HRTEM images of $\operatorname{SrTi}_{1-x} \mathrm{Cu}_{x} \mathrm{O}_{3}$ with $x=0.15$ (a), 0.20 (b) and 0.30 (c) samples. 
Figure 4 shows TPR profiles acquired from $\mathrm{SrTiO}_{3}$ and $\mathrm{SrTi}_{1-x} \mathrm{Cu}_{x} \mathrm{O}_{3}$ with $x=0.15$, 0.20 , and 0.30 during heating and under the reducing atmosphere. Catalysts showed a main peak at approximately $200{ }^{\circ} \mathrm{C}$, which can be ascribed to the reduction of surface $\mathrm{CuO}$ to metallic copper. ${ }^{17}$ This peak is more significant for $x=0.30$ as the result of higher levels of the secondary copper oxide phase in this material. For further investigation of the TPR results, all profiles were deconvoluted by using a Gaussian function (Figure S1). The profile of the catalyst with $x=0.20$ was deconvoluted into 3 peaks ( $\alpha, \beta$, and $\gamma$ in our terminology), suggesting the presence of different $\mathrm{Cu}$ species and/or $\mathrm{Cu}$ particle sizes. On the other hand, the $x=0.15$ and $x=0.30$ catalysts profiles showed only a broad peak related to the copper reduction.

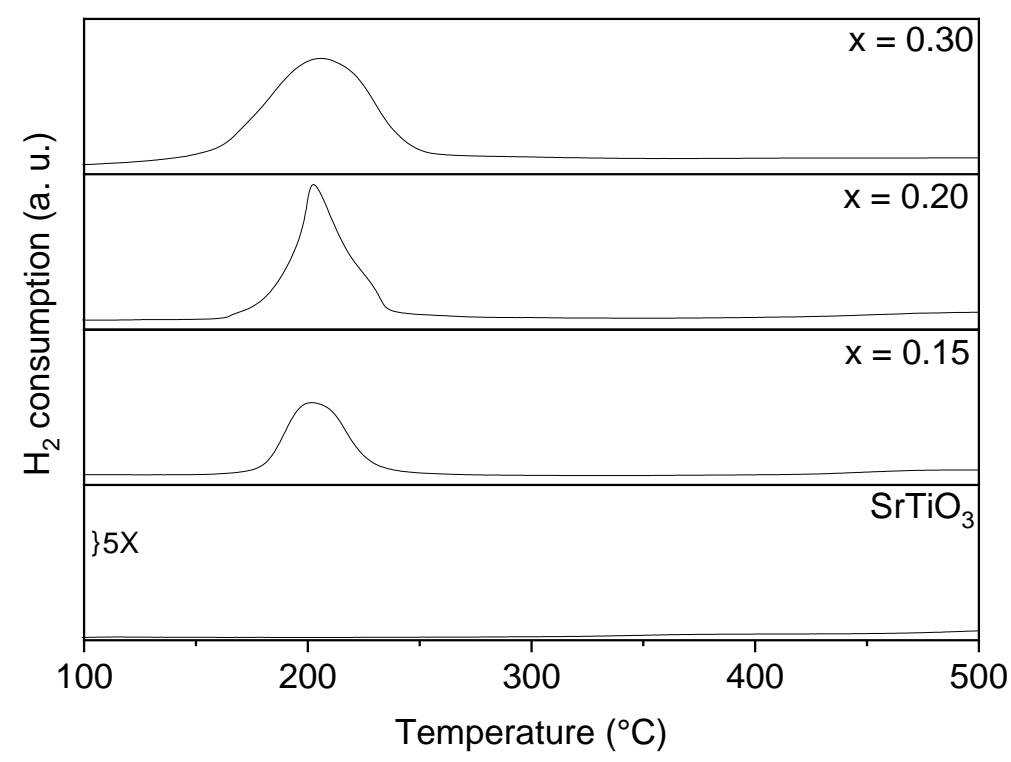

Figure 4. TPR profiles of $\mathrm{SrTiO}_{3}(x=0.00)$ and $\mathrm{SrTi}_{1-x} \mathrm{Cu}_{x} \mathrm{O}_{3}$ with $x=0.15,0.20$ and 0.30 .

Catalytic Performance. Figure 5 shows the Arrhenius-type plot of turnover frequency as a function of reaction temperature over $\mathrm{SrTi}_{1-x} \mathrm{Cu}_{x} \mathrm{O}_{3}$ materials with $x=0.15,0.20$, and 0.30 . The turnover frequency was strongly dependent on the temperature of the reaction for all samples. TOF values obtained varied from 0.05 to $1.33\left(\mathrm{~s}^{-1}\right)$, values of the same order of magnitude as those shown in the literature for $\mathrm{Cu}$-based catalysts, ${ }^{11,18,55-59}$
(Table S2 of the Supporting Information). It is essential to highlight that the $x=0.20$ catalyst showed the highest TOF for all temperatures evaluated when compared with $x=0.15$ and 0.30. Probably, the TOF achieved for the catalyst with $x=0.20$ is related to the different $\mathrm{Cu}$ species and or different particle sizes of $\mathrm{Cu}$ species when compared with the $x=0.15$ and 0.30 catalysts, as presented in Figure S1. 


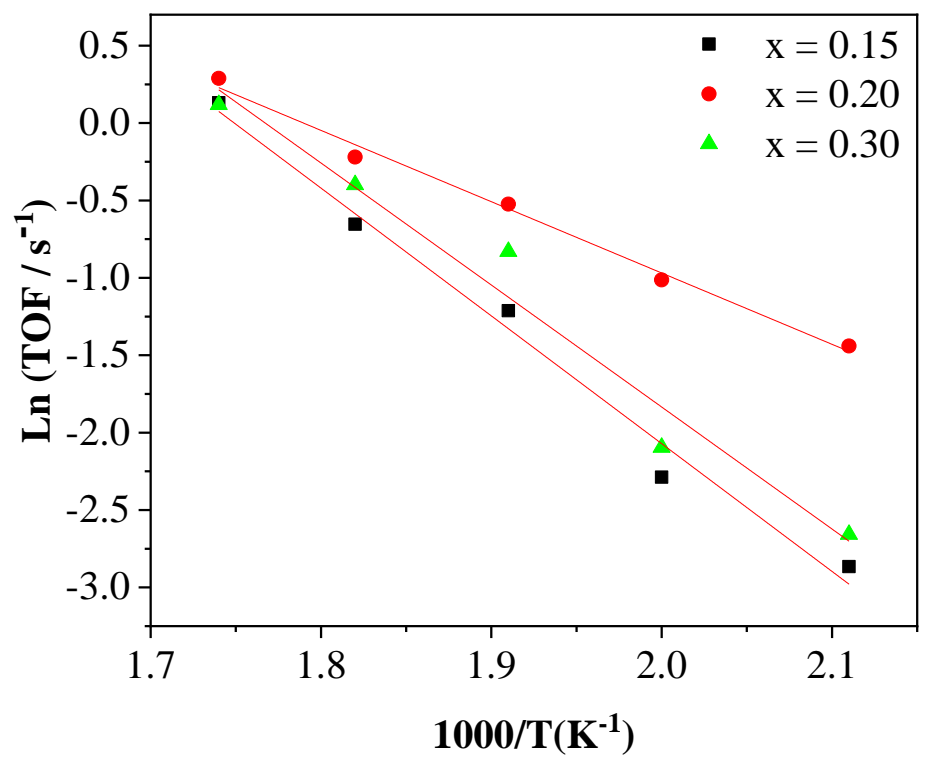

Figure 5. Arrhenius-type plots of turnover frequency for the WGS reaction over $\mathrm{SrTi}_{1-x} \mathrm{Cu}_{x} \mathrm{O}_{3}$ catalysts with $x=$ $0.15,0.20$, and 0.30 .

Figure 6 shows the WGS rate relative to the available metallic copper surface area at $200{ }^{\circ} \mathrm{C}$ and alongside the apparent activation energy (Ea) for $\mathrm{SrTi}_{1-x} \mathrm{Cu}_{x} \mathrm{O}_{3}$ catalysts. The copper metallic areas of these catalysts were 21,23 , and $24 \mathrm{~m}^{2} \cdot \mathrm{g}^{-1}$ for $x=0.15,0.20$ and
0.30, respectively. As demonstrated, increasing the $\mathrm{CuO}$ crystalline phase higher than $6.4 \%$ ( $x=0.20$ sample) on $\mathrm{SrTi}_{1-x} \mathrm{Cu}_{x} \mathrm{O}_{3}$ catalysts did not yield a monotonic increase in the TOF or WGS rate.

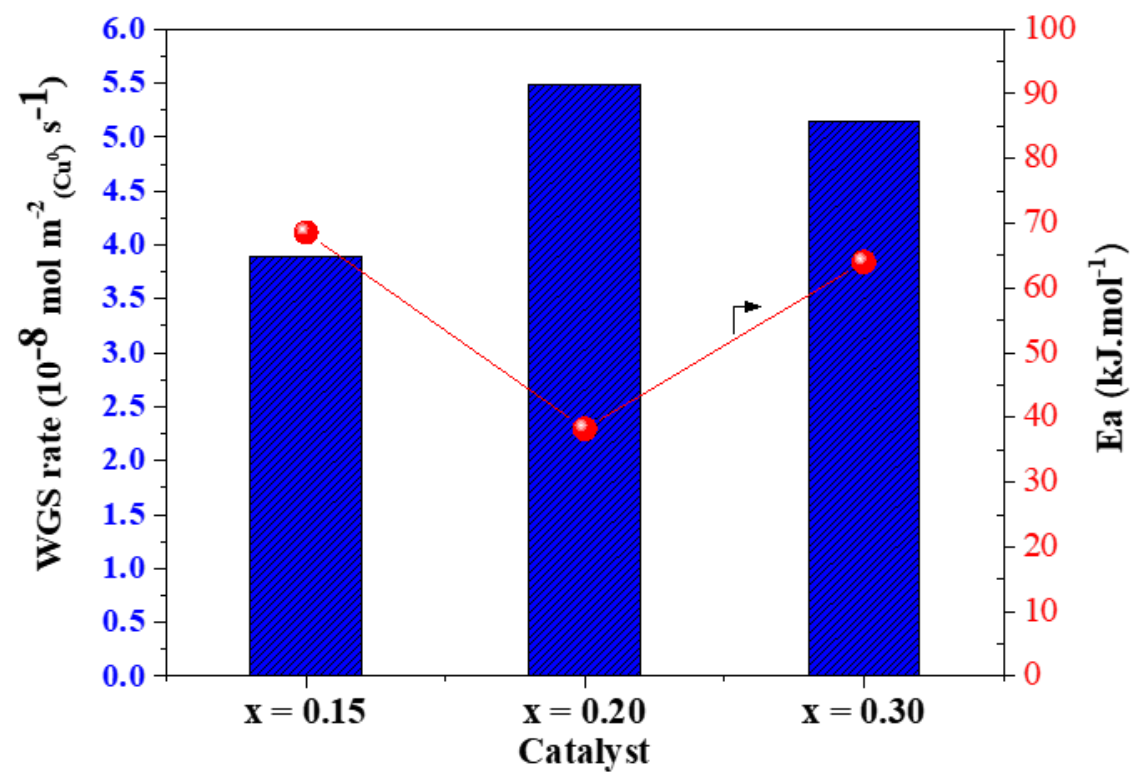

Figure 6. Rates of reaction for the overall WGS reaction, normalized per unit of copper surface area at $200{ }^{\circ} \mathrm{C}$ and apparent activation energy $(E a)$ for $\mathrm{SrTi}_{1-x} \mathrm{Cu}_{x} \mathrm{O}_{3}$ catalysts with $x=0.15,0.20,0.30$. 
The apparent activation energy $(\mathrm{Ea})$ was calculated from the slopes of the lines in the Arrhenius plots of Figure 5. The apparent activation energies reached $68.6,38.2$ and $64.0 \mathrm{~kJ} \mathrm{~mol}^{-1}$ for $\mathrm{SrTi}_{1-x} \mathrm{Cu}_{x} \mathrm{O}_{3}$ with $x=0.15$, 0.20 and 0.30 , respectively. The apparent activation energy achieved for $\mathrm{SrTi}_{1-x} \mathrm{Cu}_{x} \mathrm{O}_{3}$ with $x=0.20$ catalyst was close to the values of the best WGS catalysts presented in the literature (ca. $30-37 \mathrm{~kJ} / \mathrm{mol}$ ), ${ }^{34,59-66}$ (Supporting Information, Table S2).

It is worth emphasizing that the $x=$ 0.20 material showed an apparent Ea almost $50 \%$ lower than that of the other samples that were evaluated, and this apparent $E \mathrm{a}$ is close to the reported values for $\mathrm{Cu}_{0.2} \mathrm{Ce}_{0.8} \mathrm{O}_{2-\mathrm{y}}$ WGS catalysts $(E \mathrm{a}=34 \mathrm{~kJ} / \mathrm{mol})$ under conditions of 473-623 $\mathrm{K}$ and $\mathrm{CO} / \mathrm{H}_{2} \mathrm{O}=1 / 3 .^{34}$ The enhanced catalytic activity of the presently studied systems is further evident from a comparison with reported activation energies for WGS on pristine $\mathrm{Cu}$, reported as 63.6, 42.0 and $71 \mathrm{~kJ} / \mathrm{mol}$ for $\mathrm{Cu}(100), \mathrm{Cu}(110)$ and $\mathrm{Cu}(111)$ surfaces, respectively, ${ }^{68}$ In general, $\mathrm{Cu}$ supported on oxide supports is reported to exhibit lower WGS activation energies than pristine copper, with $E$ a values between $c a .30$ and $80 \mathrm{~kJ} \mathrm{~mol}^{-1}, 18,63,69$

Reaction rates are somewhat more challenging to compare relative to Ea values owing to the divergence in feed rates, pressures, and temperatures. The reaction rates in the present work are within the proximity of normalized reaction rates for various other metal-promoted WGS catalysts, ${ }^{63}$ (Tables S3 and S4 of the
Supporting Information). However, a meaningful quantitative comparison is rendered moot by the divergence in reaction conditions. ${ }^{63}$

The most promising WGS catalyst candidates studied to date, as mentioned before, are ceria-supported systems. The results found here do not present a significant improvement over $\mathrm{CeO}_{2}$-supported copper. However, as a first investigation into the use of perovskites in WGS catalysis, the outcomes demonstrate the viability of such systems and their merit toward WGS applications.

Additional tests at higher $\mathrm{CO}$ conversion and to evaluate the thermal stability are carried out in Figure 7. Figure 7a shows the WGS reaction results for the $\mathrm{SrTi}_{1-x} \mathrm{Cu}_{x} \mathrm{O}_{3}$ sample with $x=0.03,0.15,0.20$ and 0.30 until reaching the steady-state. For all three samples, the $\mathrm{CO}$ conversion increases substantially with increasing temperature, reaching $5,44,74$, and $46 \%$ for $x=0.03,0.15$, 0.20 , and 0.30 , respectively, at a higher temperature $\left(350^{\circ} \mathrm{C}\right)$. The low activity for the sample with $x=0.03$ indicates that the pristine $\mathrm{SrTiO}_{3}$ compound is inert for the WGS reaction. The activity for any fixed temperature is highest for $x=0.20$, as was discussed before. Figure $7 \mathrm{~b}$ further shows the stability test for $x=0.20$, which presented the best activity at $350{ }^{\circ} \mathrm{C}$ for $10 \mathrm{~h}$. The catalyst shows good stability until $6 \mathrm{~h}$ of reaction and a decrease of approximately $10 \%$ in CO conversion until $10 \mathrm{~h}$. Sintering of copper is usually a cause for catalyst deactivation. ${ }^{70}$ 

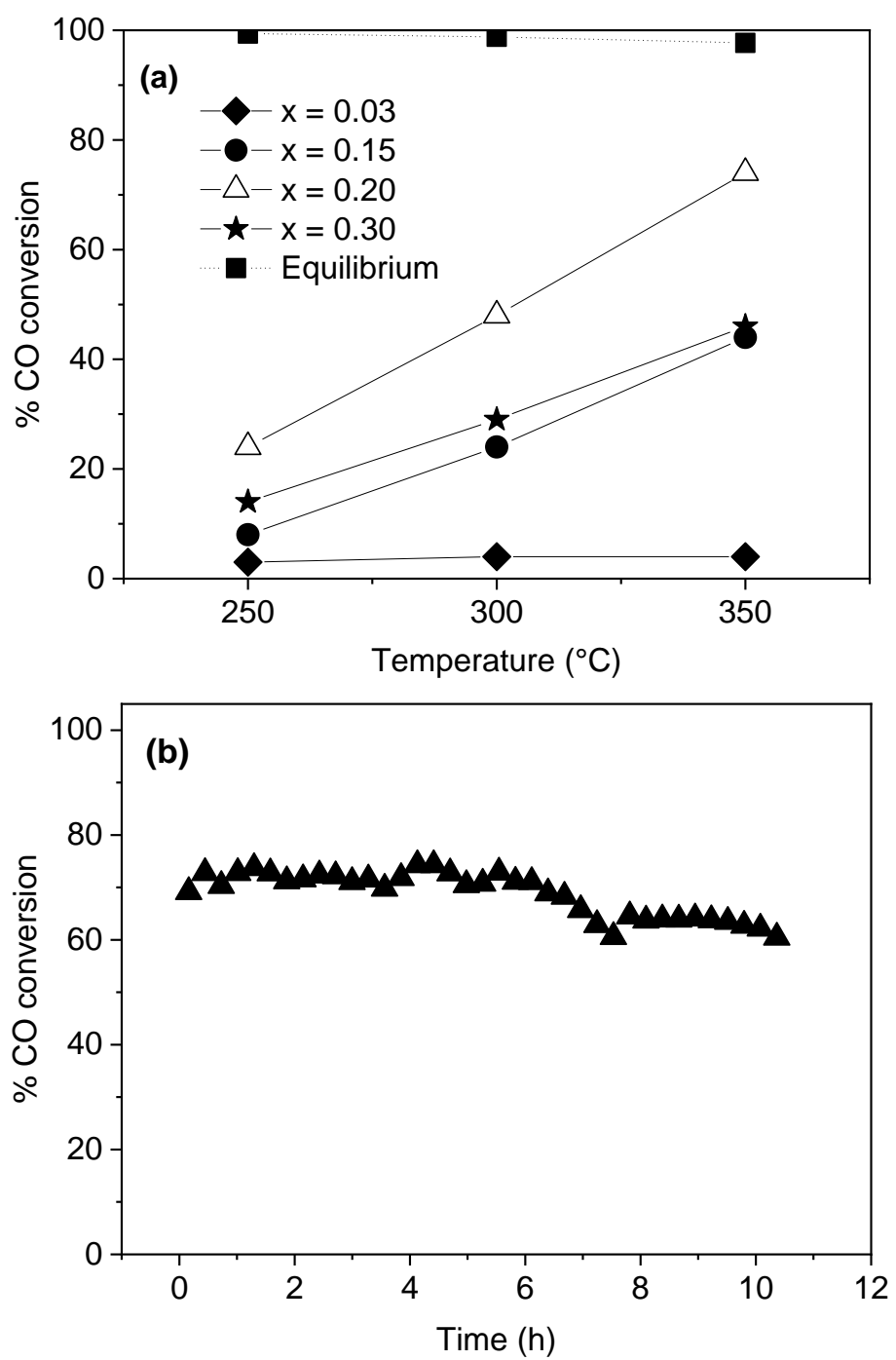

Figure 7. CO conversion on the $\mathrm{SrTi}_{1-x} \mathrm{Cu}_{x} \mathrm{O}_{3}$ catalyst with $x=0.15,0.20$ and 0.30 (a) and thermal stability test for $\mathrm{SrTi}_{1-x} \mathrm{Cu}_{x} \mathrm{O}_{3}$ catalyst with $x=0.20$ at $350{ }^{\circ} \mathrm{C}(\mathrm{b})$. Conditions: $180 \mathrm{mg}$ of catalysts under a gas atmosphere of $5 \mathrm{vol} \% . \mathrm{CO} / \mathrm{N}_{2}$ at a flux rate of $100 \mathrm{~mL} / \mathrm{min}$ and $\mathrm{CO}: \mathrm{H}_{2} \mathrm{O}=1: 3 \mathrm{molar}$ ratio.

Structural Characterization in Operando Conditions. To gain insights into the oxidation $\mathrm{Cu}$ state and the behavior of perovskite during the WGS reaction, in situ Xray diffraction and $\mathrm{X}$-ray absorption experiments were also carried out at $350{ }^{\circ} \mathrm{C}$. Figures $8 \mathrm{a}$ and $8 \mathrm{~b}$ compare the diffraction patterns of samples in the $35-45^{\circ} 2 \theta$ range at room temperature before reaction and after reduction and $1 \mathrm{~h}$ of WGS reaction at $350{ }^{\circ} \mathrm{C}$. As can be observed, the diffraction patterns showed the presence of $\mathrm{CuO}, \mathrm{Cu}, \mathrm{SrCO}_{3}$, and $\mathrm{SrTiO}_{3}$ phases before and after $1 \mathrm{~h}$ of WGS reaction, indicating that the copper is still metallic and the obtained phase assemblage is stable throughout the reaction for the examined composition range. Calculations of crystallite size using the Scherrer equation show that regardless of composition, the crystalline size of the $\mathrm{Cu}$ phase is on the order of $40 \mathrm{~nm}$. 


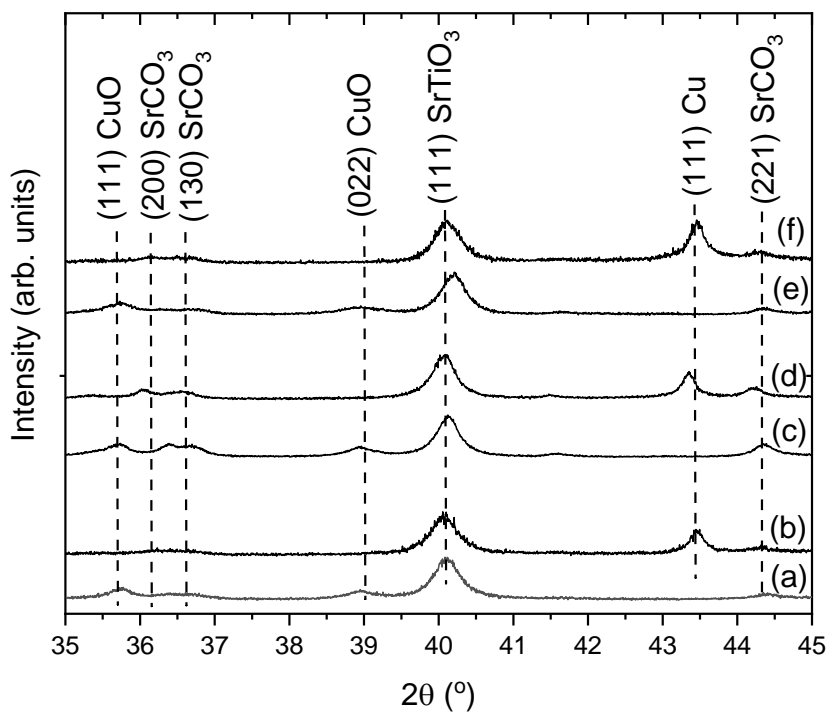

Figure 8. XRD of $\mathrm{SrTi}_{1-x} \mathrm{Cu}_{x} \mathrm{O}_{3}$ samples. $x=0.15$ sample: (a) at room temperature before reduction and reaction and (b) after reduction and $1 \mathrm{~h}$ of WGS reaction at $350{ }^{\circ} \mathrm{C} ; \boldsymbol{x}=0.20$ sample: (c) at room temperature before reduction and reaction and (d) after reduction and $1 \mathrm{~h}$ of $\mathrm{WGS}$ reaction at $350{ }^{\circ} \mathrm{C} ; x=0.30$ sample: (e) at room temperature before reduction and reaction and (f) after reduction and $1 \mathrm{~h}$ of WGS reaction at $350{ }^{\circ} \mathrm{C}$.

Figures $9 \mathrm{a}$ and $9 \mathrm{~b}$ show the XANES spectra at $\mathrm{Cu}$ of the $\mathrm{SrTi}_{1-x} \mathrm{Cu}_{x} \mathrm{O}_{3}$ samples after reduction and with the spectra collected during the WGS reaction at $350^{\circ} \mathrm{C}$. Similar to the XANES spectra of the $\mathrm{Cu}$ phase, all $\mathrm{Cu}$ atoms belonging to the $\mathrm{CuO}$ phase were reduced, and if some $\mathrm{Cu}$ species presented on the matrix of the $\mathrm{SrTiO}_{3}$ phase were not reduced, they could not be detected, probably due to the small number of $\mathrm{Cu}$ atoms inside of the $\mathrm{SrTiO}_{3}$ phase (less than $6 \mathrm{~mol} \%$ according to our previous work. ${ }^{29}$ ). These data are in good agreement with the in situ X-ray diffraction (Figure $8 b$ ). Figure $9 \mathrm{~b}$ shows the $\mathrm{Ti}$ K-edge XANES spectra of the $x=0.15$ sample collected at room temperature before reaction and after reduction, and during the WGS reaction conditions. As seen in Figure 9b, no changes in the Ti K-edge XANES spectrum are observed between measurements made under ambient conditions and during the WGS reaction, allowing us to conclude that only the copper atoms were reduced while the oxidation state and the local structure of titanium atoms remained stable during the WGS reaction. This result is in line with the XRD data, which show that the long-range order structure of the $\mathrm{SrTiO}_{3}$ perovskite phase remains stable under the conditions of the WGS reaction.
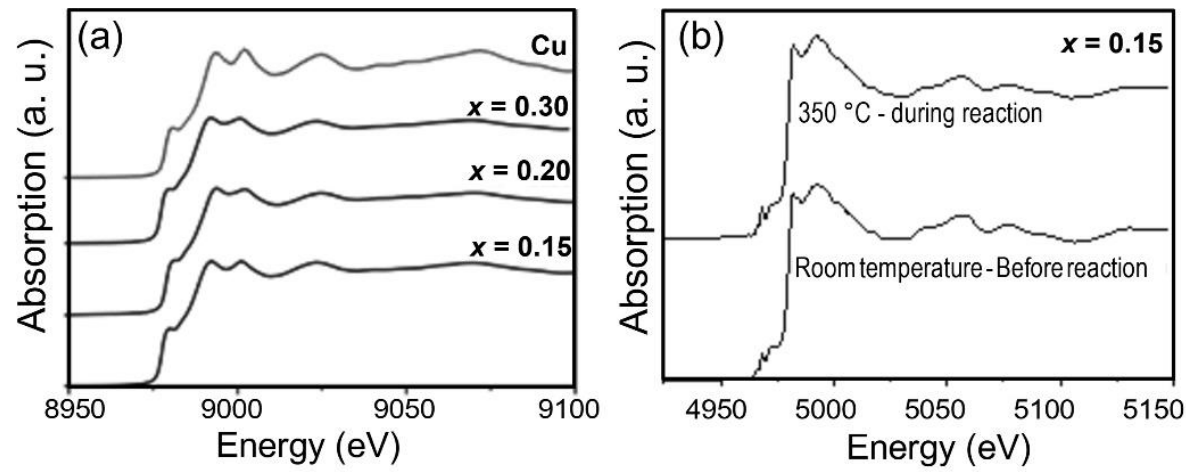

Figure 9. (a) In situ $\mathrm{Cu}$ K-edge XANES spectra of $\mathrm{SrTi}_{1-x} \mathrm{Cu}_{x} \mathrm{O}_{3}$ samples after reduction and $1 \mathrm{~h}$ of WGS reaction at $350{ }^{\circ} \mathrm{C}$. (b) XANES spectra at the Ti edge of sample $x=0.15$ at room temperature and after reduction and 1 $h$ of WGS reaction at $350{ }^{\circ} \mathrm{C}$. 


\section{Cu Aggregation Tendencies from DFT}

Calculations. Computational analysis based on DFT was conducted to glean new insights into the behavior of $\mathrm{Cu}$ within the $\mathrm{SrTiO}_{3}$ matrix that initiates the observed $\mathrm{Cu}$ agglomerates' growth. The formation energy $\left(E_{\mathrm{f}}\right)$ of incorporating $\mathrm{Cu}$ atoms in the $\mathrm{SrTiO}_{3}$ host matrix was calculated as a function of O's chemical potential (Figure 10a) and is shown in Figure 10b. Under the O-rich environment, Point $B, \mathrm{Cu}_{\mathrm{Ti}}$ species with an $E_{\mathrm{f}}$ of $0.481 \mathrm{eV}$ were comfortably more stable than $\mathrm{Cu}_{\mathrm{sr}}\left(E_{\mathrm{f}}=\right.$ $1.706 \mathrm{eV})$ and $\mathrm{Cu}_{\text {Int }}\left(E_{\mathrm{f}}=4.945 \mathrm{eV}\right)$. The sequence of stabilization was, however, reversed under the O-poor environment, with $\mathrm{Cu}_{\text {Int }}$ being the most stable site with an $E_{\mathrm{f}}$ of $4.756 \mathrm{eV}$. Consequently, since our samples were treated under an oxygen environment at $500{ }^{\circ} \mathrm{C}$ during the synthesis, we can assume that all $\mathrm{Cu}$ atoms initially substituted a $\mathrm{Ti}$ ion. The preference of $\mathrm{Cu}$ substituting Ti under the O-rich environment has also been observed for samples prepared by solid-state reaction ${ }^{25}$ and has been predicted in DFT calculations based on the GGA method. ${ }^{27}$ In all these cases, the oxidation of $\mathrm{Cu}$ dopant can be inferred from the DFT site projected spin population on $\mathrm{Cu}$, which is 0 , pertaining to $\mathrm{d}^{10}$ electronic configuration, for $\mathrm{Cu}_{\mathrm{Int}}$ and $\mathrm{Cu}_{\mathrm{Sr}}$, and $0.952 e$, pertaining to $\mathrm{d}^{9}$ electronic configuration, for $\mathrm{Cu}_{\mathrm{Ti}}$, indicating that $\mathrm{Cu}_{\mathrm{Int}}$ and $\mathrm{Cu}_{\mathrm{Sr}}$ have an oxidation state of +1 , while $\mathrm{Cu}_{\text {Ti }}$ has an oxidation state of +2 .

In the next stage, the aggregation of the $\mathrm{Cu}_{\mathrm{Ti}}$ species was studied to examine the propensity toward $\mathrm{CuO}$ secondary phase formation. This was achieved by varying the $\mathrm{Cu}-\mathrm{Cu}$ distance in a supercell containing two $\mathrm{Cu}_{\mathrm{Ti}}$ atoms and monitoring the total energy. The configurations are shown in Figure 10c. In each configuration, one $\mathrm{Cu}$ atom was placed at site $\mathbf{0}$, while another $\mathrm{Cu}$ atom was placed at sites $\mathbf{a}, \mathbf{b}, \mathbf{c}$, and $\mathbf{d}$, for which the total relative energy $\left(E_{\mathrm{R}}\right)$ is given in Figure 10d. The total energy of the supercells containing two $\mathrm{Cu}_{\mathrm{Ti}}$ varies only marginally as a function of $d_{\mathrm{Cu}-\mathrm{Cu}}$. For instance, the shortest possible
$d_{\mathrm{Cu}-\mathrm{Cu}}$ for $\mathrm{Cu}_{\mathrm{Ti}}$ was $3.95 \AA$, for which the total energy was only $0.064 \mathrm{eV}$ higher than that of the most stable configuration $\left(d_{\mathrm{Cu}-\mathrm{Cu}}=8.88\right.$ Å). Given the weak relationship between the total energy and $d_{\mathrm{Cu}-\mathrm{Cu}}$ for $\mathrm{Cu}_{\mathrm{Ti}}$, the distribution of $\mathrm{Cu}_{\text {Ti }}$ in the $\mathrm{SrTiO}_{3}$ host lattice is predicted to be homogeneous for dilute $\mathrm{Cu}$ concentrations.

In contrast, for higher $\mathrm{Cu}$ concentrations, the formation of secondary $\mathrm{CuO}$ or $\mathrm{CuO}_{2}$ phases or ternary oxides is likely dominated by random phase percolation. ${ }^{71}$ The same trend was also predicted for $\mathrm{Cu}_{\mathrm{Ti}}$ at the $\mathrm{SrTiO}_{3}$ (100) surface, as shown in Figure S2. Of particular note, the absence of a strong thermodynamic driving force for either aggregation or dispersion of $\mathrm{Cu}_{\mathrm{Ti}}$ species suggests that the local structure of copper species in $\mathrm{SrTiO}_{3}$ prepared under Orich conditions is likely to be sensitive to the applied synthesis protocols. The synthesis methodology used here is conducive to steric entrapment of cations and would be expected to yield lower levels of phase segregation for smaller $\mathrm{Cu}$ concentrations, as seen in the EDX mapping relative to other synthesis methods that may be prone to inhomogeneous crystallization during formation. ${ }^{72}$

Consequently, the agglomeration observed in the STEM images is driven by random percolation growth along with the higher likelihood of $\mathrm{Cu}_{\text {Ti }}$ ions occupying nearest neighbor sites as $\mathrm{Cu}$ concentration increases. For the sample with $x=0.15$, the low turnover frequency can be attributed to the smaller number of active sites. For $x=$ 0.20 , a higher $\mathrm{Cu}_{\mathrm{Ti}}$ concentration increases the active sites and, in turn, the turnover frequency. For $x=0.30$, the ever-larger agglomeration of $\mathrm{Cu}_{\mathrm{Ti}}$, and therefore the resultant secondary $\mathrm{CuO}$ areas on the surface, as seen in the EDX mapping of $\mathrm{Cu}$ (Figure 2), eventually reduces the exposed active sites (metallic $\mathrm{Cu}$ ) available for the catalytic reaction, reducing the turnover frequency. 

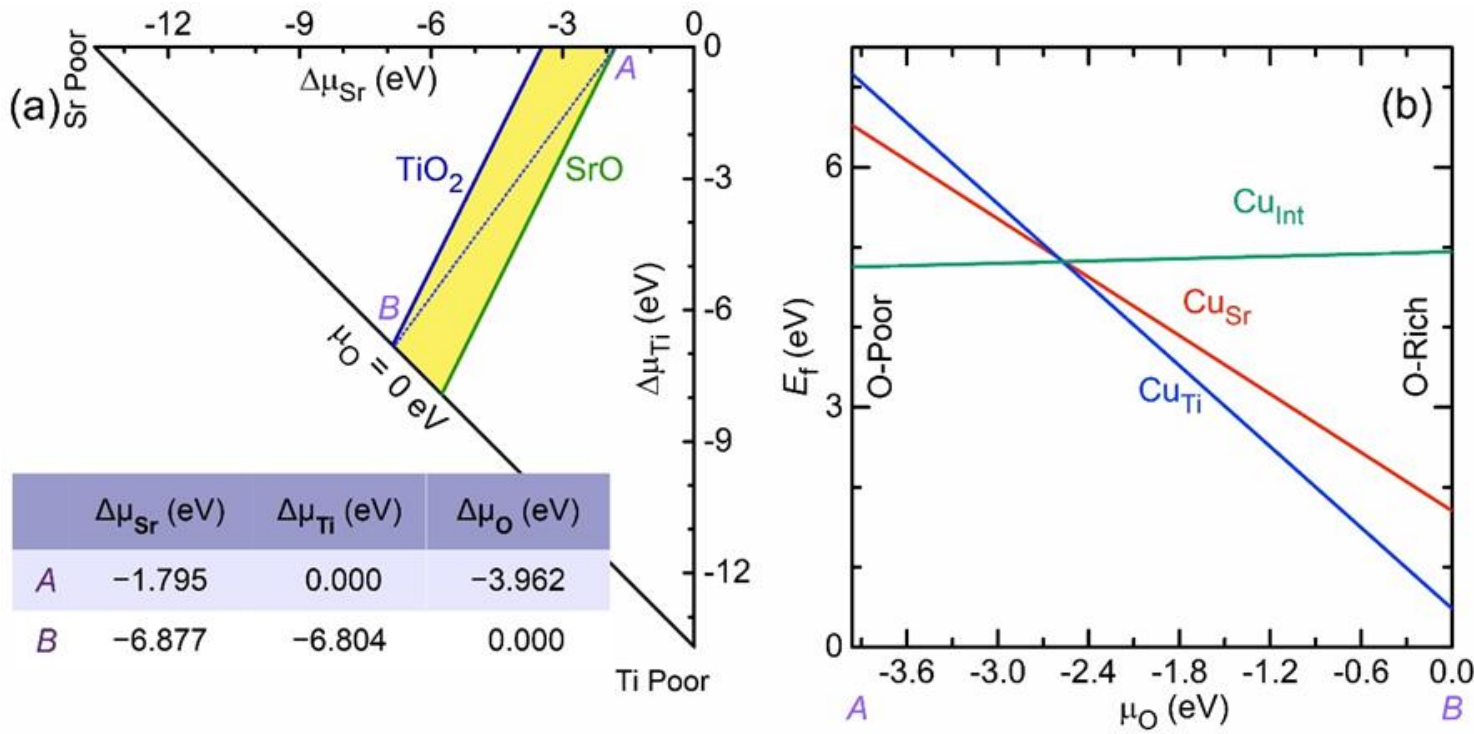

(c)
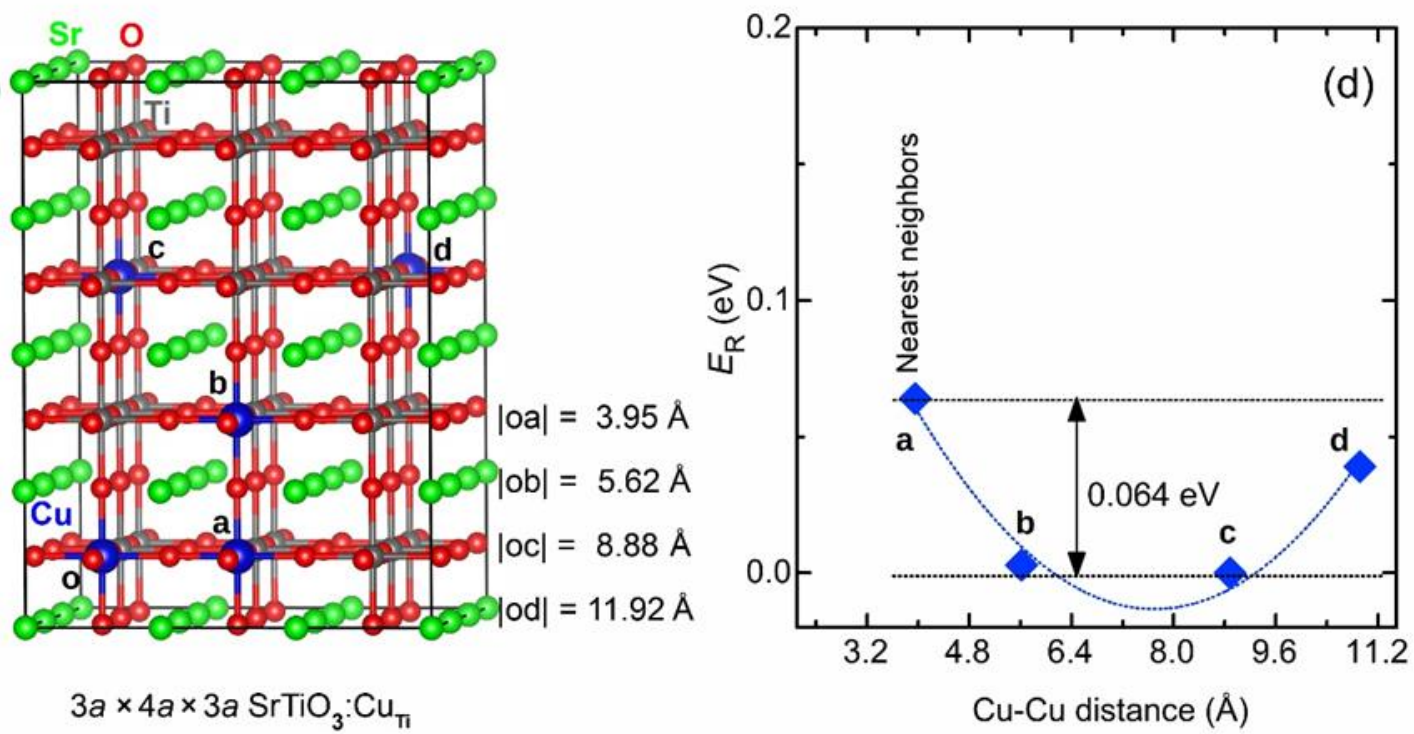

Figure 10. (a) The phase diagram for cubic $\mathrm{SrTiO}_{3}$ at zero Kelvin. The shaded area represents the chemical stability range of $\mathrm{SrTiO}_{3}$. The chemical potentials at $A$ and $B$ are referred to as oxygen-poor and oxygen-rich, respectively. $(b)$ The formation energy $\left(E_{\mathrm{f}}\right)$ of $\mathrm{Cu}$ atoms in the $\mathrm{SrTiO}_{3}$ host lattice under the O-poor environment (left side) and $\mathrm{O}$-rich environment (right site). (c) Configurations containing two $\mathrm{Cu}$ atoms that were used to study the $\mathrm{Cu}$ Ti aggregation tendency. In each configuration, one $\mathrm{Cu}$ atom is located at site $\mathrm{o}$, while the second $\mathrm{Cu}$ ion is located at either $\mathbf{a}, \mathrm{b}$, c, or $\mathrm{d}$. (d) The relative total energy $\left(E_{\mathrm{R}}\right)$ for configurations with two $\mathrm{Cu}$ atoms as a function of $\mathrm{Cu}-\mathrm{Cu}$ distance. $E_{\mathrm{R}}$ is the total energy value given relative to the most stable configuration.

Furthermore, the DFT formation enthalpy of $\mathrm{SrTiO}_{3}$, defined as $\Delta H^{f}\left(\mathrm{SrTiO}_{3}\right)=E_{\mathrm{t}}\left(\mathrm{SrTiO}_{3}\right)-E_{\mathrm{t}}(\mathrm{Sr})-$ $E_{\mathrm{t}}(\mathrm{Ti})-1.5 E_{\mathrm{t}}\left(\mathrm{O}_{2}\right)$, was found to be -13.681 $\mathrm{eV}$ per formula unit (f.u. ), while the formation enthalpy of $\mathrm{CuO}, \Delta H^{f}(\mathrm{CuO})=E_{\mathrm{t}}(\mathrm{CuO})-$ $E_{\mathrm{t}}(\mathrm{Cu})-0.5 E_{\mathrm{t}}\left(\mathrm{O}_{2}\right)$, was calculated to be merely -0.189 eV/f.u. The significantly smaller (negative) formation enthalpy of $\mathrm{CuO}$ with respect to that of $\mathrm{SrTiO}_{3}$ ensures that in the catalysis reduction step, $\mathrm{CuO}$ is preferentially reduced rather than $\mathrm{SrTiO}_{3}$, leaving exposed catalytically active metallic $\mathrm{Cu}$ sites on the $\mathrm{SrTiO}_{3}$ surface. The presence of metallic $\mathrm{Cu}$ on $\mathrm{SrTiO}_{3}$ 's surface is wellknown to facilitate the $\mathrm{CO}$ adsorption, which is the first step of the WGS catalytic reactions, ${ }^{73,74}$ as the affinity of $\mathrm{CO}$ to pristine $\mathrm{SrTiO}_{3}$ is rather weak. ${ }^{75}$ 
Figure 11 shows the electronic density of states (DOS) of the Cu-modified $\mathrm{SrTiO}_{3}$. The valence band is mainly composed of $\mathrm{O} 2 \mathrm{p}$ states, while the conduction band is primarily composed of $\mathrm{Ti} 3 \mathrm{~d}$ states. With $\mathrm{Cu}_{\mathrm{Ti}}$ species, the octahedral coordination of the original $\mathrm{Ti}$ site splits the $\mathrm{Cu} 3 \mathrm{~d}$ states, therefore creating an empty band of the $e_{g}$ states in the middle of the fundamental bandgap, resulting in a deep copper band that manifests as catalytically active levels in $\operatorname{SrTi}_{1-x} \mathrm{Cu}_{x} \mathrm{O}_{3}$. These copper states can offer chemically labile empty orbitals for accepting electrons from CO's $5 \sigma$ molecular orbitals, as shown in the inset, and facilitate the chemisorption of $\mathrm{CO}$ molecules on the $\mathrm{Cu}$-rich areas of the surface. ${ }^{76,77}$

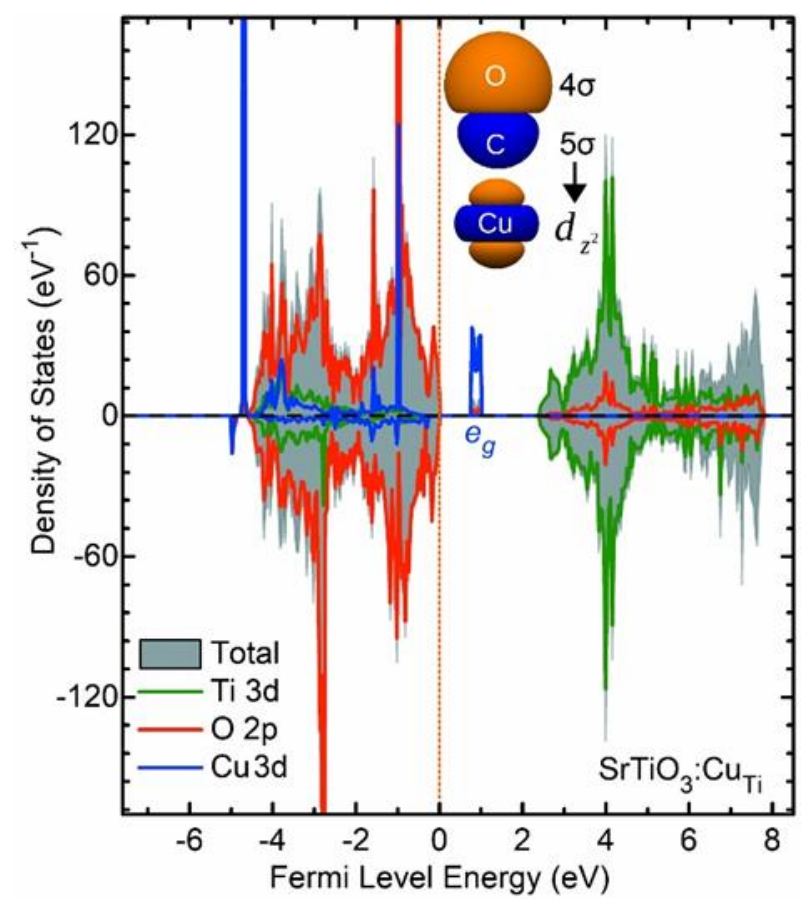

Figure 11. The total and partial density of states of $\mathrm{SrTiO}_{3}: \mathrm{Cu}_{\mathrm{Ti}}$. Copper's states are magnified by a factor of 10 for clarity. The inset schematically shows how the labile empty $\mathrm{Cu}$ states can facilitate the adsorption of the $\mathrm{CO}$ molecule produced with the Orbitals Viewer package. ${ }^{78}$

\section{CONCLUSIONS}

$\mathrm{Cu}$-modified $\mathrm{SrTiO}_{3} \quad\left(\mathrm{SrTi}_{1-x} \mathrm{Cu}_{x} \mathrm{O}_{3}\right)$ was studied as a novel material for water-gas shift (WGS) catalysis. Among the samples prepared here, with different copper contents, there are no significant differences in shortand long-range order and oxidation state, both in ambient and in reaction conditions. Using DFT calculations, it was demonstrated that $\mathrm{Cu}$ species are likely to occupy $\mathrm{Ti}$ sites in the $\mathrm{SrTiO}_{3}$ host matrix under the synthesis conditions applied here. Experimental results show a combination of copper in the host lattice in addition to a precipitating secondary copper oxide phase on the surface, which is readily reduced to a metallic state under WGS reaction conditions. $\mathrm{SrTi}_{1-x} \mathrm{Cu}_{x} \mathrm{O}_{3}$ materials prepared with $x=0.20$ exhibited higher WGS rates relative to the lower apparent activation energy relative to materials of lower and higher $\mathrm{Cu}$ content. The enhanced catalytic performance for the $x=0.20$ catalyst is related to the optimized dispersion of $\mathrm{Cu}^{0}$ sites on the perovskite lattice, which promotes WGS reactions. Catalytic activity was found to compare favorably with earlier studies of metal-loaded oxide WGS catalysts. The results here serve to establish the appropriateness of $\mathrm{Cu}$-substituted strontium titanate materials for use as water gas shift catalysts and further highlight the central role of available metallic sites in governing the kinetics of catalyzed reactions. 


\section{ASSOCIATED CONTENT}

Supporting Information

Experimental evaluation of the amount of metallic $\mathrm{Cu}$, lattice parameters of $\mathrm{SrTi}_{1-x} \mathrm{Cu}_{x} \mathrm{O}_{3}$, activation energies, turnover frequencies, and reaction rates compared with the literature, permissible chemical potential $(\Delta \mu) \quad$ values for density functional calculations, calculated segregation tendency among $\mathrm{Cu}$ atom on the surface of $\mathrm{SrTiO}_{3}$, calculated segregation tendency of $\mathrm{Cu}$ under O-poor environment

\section{ACKNOWLEDGMENTS}

The authors are grateful for the financial support provided by São Paulo Research Foundation - FAPESP (grant 2013/07296-2, 2017/08293-8 and 2015/06246-7) and National Council for Scientific and Technological Development - CNPq (grants 304498/2013-0, 304883/2016-6 and 140631/2013-5). Our thanks are also extended to the Brazilian Synchrotron Light Laboratory (LNLS) for the use of its XAFS2 and XPD beamline experimental facilities (proposal numbers 15960 and 17001). The authors are also grateful to Alessandra F. Lucredio for TPR measurements and Vitor A. S. Mendes for the use of the transmission electron microscope. Computational resources were provided by supercomputers at the Center for Computational Sciences at the University of Tsukuba, Japan.

\section{REFERENCES}

(1) LeValley, T.L.; Richard, A. R.; Fan, M. H. The progress in water gas shift and steam reforming hydrogen production technologies - A review. Int. J. Hydrogen Energy 2014, 39, 16983-17000.
(2) Sharaf, O. Z.; Orhan, M. F. An overview of fuel cell technology: Fundamentals and applications. Renew. Sust. Energy Rev. 2014, 32, 810-853.

(3) Gradisher, L.; Dutcher, B.; Fan, M. Catalytic hydrogen production from fossil fuels via the water gas shift reaction. Appl. Energy 2015, 139, 335-349.

(4) Ratnasamy, C.; Wagner, J. P. Water Gas Shift Catalysis.Catal. Rev. 2009, 51, 325-440.

(5) Tanaka, Y.; Utaka, T.; Kikuchi, R.; Takeguchi, T.; Sasaki, K.; Eguchi, K. Water gas shift reaction for the reformed fuels over $\mathrm{Cu} / \mathrm{MnO}$ catalysts prepared via spinel-type oxide. J. Catal. 2003, 215, 271-278.

(6) Tanaka, Y.; Utaka, T.; Kikuchi, R.; Sasaki, K.; Eguchi, K. Water-gas shift reaction over $\mathrm{Cu}-$ based mixed oxides for $\mathrm{CO}$ removal from the reformed fuels. Appl. Catal. A 2003, 242, $287-$ 295.

(7) Tanaka, Y.; Takeguchi, R.; Kikuchi, R.; Eguchi, K. Influence of preparation method and additive for $\mathrm{Cu}-\mathrm{Mn}$ spinel oxide catalyst on water gas shift reaction of reformed fuels. Appl. Catal. A 2005, 279, 59-66.

(8) Tabakova, T.; Idakiev, V.; Avgouropoulos, G.; Papavasiliou, J.; Manzoli, M.; Boccuzzi, F.; Ioannides, T. Highly active copper catalyst for low-temperature water-gas shift reaction prepared via a $\mathrm{Cu}-\mathrm{Mn}$ spinel oxide precursor. Appl. Catal. A 2013, 451, 184-191.

(9) Li, Y.; Fu, Q.; Flytzani-Stephanopoulos, M. Low-temperature water-gas shift reaction over $\mathrm{Cu}-$ and $\mathrm{Ni}$-loaded cerium oxide catalysts. Appl. Catal. B 2000, 27, 179-191.

(10) Pradhan, S.; Reddy, A. S.; Devi, R. N.; Chilukuri, S. Copper-based catalysts for water gas shift reaction: Influence of support on their catalytic activity. Catal. Today 2009, 141, 72-76.

(11) Maciel, C. G.; Silva, T. de F.; Assaf, E. M.; Assaf, J. M. Hydrogen Production and Purification from the Water-Gas Shift Reaction on $\mathrm{CuO} / \mathrm{CeO}_{2}-\mathrm{TiO}_{2}$ Catalysts. Appl. Energy 2013, $112,52-59$. 
(12) Lin, X. Y.; Chen, C. Q.; Ma, J. T.; Fang, X.; Zhan, Y. Y.; Zheng, Q. Promotion effect of $\mathrm{Nb}^{5+}$ for $\mathrm{Cu} / \mathrm{CeO}_{2}$ water-gas shift reaction catalyst by generating mobile electronic carriers. Int. $J$. Hydrogen Energy 2013, 38, 11847-11852.

(13) Jeong, D.-W.; Na, H.-S.; Shim, J.-O.; Jang, W.-J.; Roh, H.-S. A crucial role for the CeO2$\mathrm{ZrO}_{2}$ support for the low temperature water gas shift reaction over $\mathrm{Cu}-\mathrm{CeO}_{2}-\mathrm{ZrO}_{2}$ catalysts. Catal. Sci. Tech. 2015, 5, 3706-3713.

(14) Jeong, D.-W.; Jang, W.-J.; Shim, J.-O.; Han, H.-S.; Roh, H.-S.; Jung, U. H.; Yoon, W. L. Low-temperature water-gas shift reaction over supported $\mathrm{Cu}$ catalysts. Renew. Energy 2014, 65, 102-107.

(15) Vovchok, D.; Guild, C. J.; Llorca, J.; Xu, W. Q.; Jafari, T.; Toloueinia, P.; Kriz, D; Waluyo, I.; Palomino, R. M.; Rodriguez, J. A.; Suib, S. L.; Senanayake, S.D. Cu supported on mesoporous ceria: water gas shift activity at low $\mathrm{Cu}$ loadings through metal-support interactions. Phys. Chem. Chem. Phys. 2017, 19, 17708-17717.

(16) Elias, J. S.; Artrith, N.; Bugnet, M.; Giordano, L.; Botton, G. A.; Kolpak, A. M.; Shao-Horn, Y. Elucidating the Nature of the Active Phase in Copper/Ceria Catalysts for CO Oxidation. ACS Catal. 2016, 6, 1675-1679.

(17) Plata, J. J.; Graciani, J.; Evans, J.; Rodriguez, J. A.; Sanz, J. F. Cu Deposited on $\mathrm{CeO}_{\mathrm{x}}-$ Modified $\mathrm{TiO}_{2}(110)$ : Synergistic Effects at the Metal-Oxide Interface and the Mechanism of the WGS Reaction. ACS Catal. 2016, 6, 46084615.

(18) Jeong, D. W.; Na, H. S.; Shim, J. O.; Jang, W. J.; Roh, H. S.; Jung, U. H.; Yoon W. L. Hydrogen production from low temperature WGS reaction on co-precipitated $\mathrm{Cu}-\mathrm{CeO}_{2}$ catalysts: An optimization of $\mathrm{Cu}$ loading. Int. J. Hydrogen Energy 2014, 39, 9135-9142.

(19) Rodriguez, A. A.; Graciani, J.; Evans, J.; Park, J. B.; Yang, F.; Stacchiola, D.; Senanayake, S. D.; Ma, S. G.; Perez, M.; Liu, P.; Sanz, J. F.; Hrbek J. Water-Gas Shift Reaction on a Highly Active Inverse $\mathrm{CeO}_{\mathrm{x}} / \mathrm{Cu}(111)$ Catalyst: Unique Role of Ceria Nanoparticles. Angew. Chem. Int. Ed. 2009, 48, 8047-8050.
(20) Enterkin, J. A.; Setthapun, W.; Elam, J. W.; Christensen, S. T.; Rabuffetti, F. A.; Marks, L. D.; Stair, P. C.; Poeppelmeier, K. R.; Marshall, C. L. Propane Oxidation over Pt/SrTiO Nanocuboids. ACS Catal. 2011, 1, 629-635.

(21) Wang, H.; Lu, J. L.; Marshall, C. L.; Elam, J. W.; Miller, J. T.; Liu, H. B.; Enterkin, J. A.; Kennedy, R. M.; Stair, P. C.; Poeppelmeier, K. R.; Marks, L. D. In situ XANES study of methanol decomposition and partial oxidation to syn-gas over supported Pt catalyst on $\mathrm{SrTiO}_{3}$ nanocubes. Catal. Today 2014, 237,71-79.

(22) Gurav, H. R.; Bobade, R.; Das, V. L.; Chilukuri, S. Carbon dioxide reforming of methane over ruthenium substituted strontium titanate perovskite catalysts. Indian J. Chem. A 2012, 51, 1339-1347.

(23) Lopez-Suarez, F. E; Illan-Gomez, M. J.; Bueno-Lopez, A.; Anderson, J. A. $\mathrm{NO}_{\mathrm{x}}$ storage and reduction on $\mathrm{SrTiCuO}_{3}$ perovskite catalyst studied by operando DRIFTS. Appl. Catal. B 2011, 104, 261-267.

(24) Lopez-Suarez, F. E.; Parres-Esclapez, S.; Bueno-Lopez, A.; Illan-Gomez, M. J.; Ura, B.; Trawczynski, J. Role of surface and lattice copper species in copper-containing $(\mathrm{Mg} / \mathrm{Sr}) \mathrm{TiO}_{3}$ perovskite catalysts for soot combustion. Appl. Catal. B 2009, 93, 82-89.

(25) Glisenti, A.; Natile, M. M.; Carlotto, S.; Vittadini, A. Co- and Cu-Doped Titanates: Toward a New Generation of Catalytic Converters. Catal. Lett. 2014, 144, 1466-1471.

(26) Jain, N.; Roy, A.; De, A. Ba-addition induced enhanced surface reducibility of $\mathrm{SrTiO}_{3}$ : implications on catalytic aspects. Nanoscale $A d v$. 2019, 1, 4938-4946.

(27) Carlotto, S.; Natile, M. M.; Glisenti, A.; Vittadini, A. Catalytic mechanisms of NO reduction in a $\mathrm{CO}-\mathrm{NO}$ atmosphere at $\mathrm{Co}-\mathrm{and} \mathrm{Cu}-$ doped $\mathrm{SrTiO}_{3}$ (100) surfaces. J. Phys. Chem. C 2018, 122, 449-454.

(28) Bai, L.; Polo-Garzon, F.; Bao, Z; Luo, S.; Moskowitz, B. M.; Tian, H.; Wu, Z. Impact of Surface Composition of $\mathrm{SrTiO}_{3}$ Catalysts for 
Coletta, Vitor C., et al. "Cu-Modified SrTiO3 Perovskites Toward Enhanced Water-Gas Shift Catalysis: A Combined Experimental and Computational Study." ACS Applied Energy Materials (2021), 4, 1, 452-461

Oxidative Coupling of Methane. ChemCatChem 2019, 11(8), 2107-2117.

(29) Coletta, V. C.; Marcos, F. C. F.; Nogueira, F. G. E; Bernardi, M. I. B.; Michalowicz, A.; Goncalves, R. V.; Assaf, E. M.; Mastelaro V.R. In situ study of copper reduction in $\mathrm{SrTi}_{1-\mathrm{x}} \mathrm{Cu}_{\mathrm{x}} \mathrm{O}_{3}$ nanoparticles. Phys. Chem. Chem. Phys. 2016, $18,2070-2079$.

(30) da Silva, L. F.; Maia, L. J. Q.; Bernardi, M. I. B.; Andres, J. A.; Mastelaro, V .R. An improved method for preparation of $\mathrm{SrTiO}_{3}$ nanoparticles. Mater. Chem. Phys. 2011, 125, 168-173.

(31) Larson, A.C.; Von Dreele, R. General Structure Analysis System (GSAS) Manual, in: LANSCE, MS-H805 Los Alamos National Laboratory, Los Alamos, NM 87545, 1994.

(32) Sanchez, J. M.; Marono, M.; Cillero, D.; Montenegro, L.; Ruiz, E. Laboratory- and benchscale studies of a sweet water-gas-shift catalyst for $\mathrm{H}-2$ and $\mathrm{CO}_{2}$ production in pre-combustion $\mathrm{CO}_{2}$ capture. Fuel 2013, 114, 191-198.

(33) Din, I. U.; Shaharun, M. S.; Subbarao, D.; Naeem, A.; Hussain, F. Influence of niobium on carbon nanofibres based $\mathrm{Cu} / \mathrm{ZrO}_{2}$ catalysts for liquid-phase hydrogenation of $\mathrm{CO}_{2}$ to methanol. Catal. Today 2016, 259, 303-311.

(34) Kusar, H.; Hocevar, S.; Levec, J. Kinetics of the water-gas shift reaction over nanostructured copper-ceria catalysts. Appl. Catal. B 2006, 63, 194-200.

(35) Panagiotopoulou, P.; Kondarides D. I. Effect of morphological characteristics of $\mathrm{TiO}_{2^{-}}$ supported noble metal catalysts on their activity for the water-gas shift reaction. J. Catal. 2004, $225,327-336$.

(36) Twigg, M.V.; Catalyst Handbook, Manson Pub. London, UK , 1996.

(37) Elliott, J. R.; Lira, C.T. Introductory Chemical Engineering Thermodynamics, Pearson, 2nd edn., 2012.

(38) Hanaor, D. A. H.; Assadi, M. H. N.; Li, S.; Yu, A. B.; Sorrell, C. C. Ab initio study of phase stability in doped $\mathrm{TiO}_{2}$. Comput. Mech. 2012, 50, 185-194.

(39) Blochl, P. E. Projector Augmented-Wave Method. Phys. Rev. B 1994, 50, 17953-17979.

(40) Kresse, G.; Furthmuller, J. Efficient iterative schemes for ab initio total-energy calculations using a plane-wave basis set. Phys. Rev. B 1996, 54, 11169-11186.

(41) Kresse, G.; Joubert, D. From ultrasoft pseudopotentials to the projector augmentedwave method. Phys. Rev. B 1999, 59, 1758-1775.

(42) Kresse, G.; Furthmuller, J. Efficiency of abinitio total energy calculations for metals and semiconductors using a plane-wave basis set. Comput. Mater. Sci. 1996, 6, 15-50.

(43) Perdew, J. P.; Burke, K.; Ernzerhof, M. Generalized gradient approximation made simple. Phys. Rev. Lett. 1996, 77, 3865-3868.

(44) Dudarev, S. L.; Botton, G. A.; Savrasov, S. Y.; Humphreys, C. J.; Sutton, A. P. Electronenergy-loss spectra and the structural stability of nickel oxide: An LSDA+U study. Phys. Rev. B 1998, 57, 1505-1509.

(45) Cuong, D. D.; Lee, B.; Choi, K. M.; Ahn, H. S.; Han, S.; Lee, J. Oxygen vacancy clustering and electron localization in oxygen-deficient $\mathrm{SrTiO}_{3}$ : LDA+U study. Phys. Rev. Lett. 2007, 98, 115503.

(46) Rivero, P.; Loschen, C.; Moreira, I. D. R.; Illas, F. Performance of Plane-Wave-Based LDA plus U and GGA plus U Approaches to Describe Magnetic Coupling in Molecular Systems. $J$. Comput. Chem. 2009, 30, 2316-2326.

(47) Assadi, M. H. N.; Hanaor, D. A. H. Theoretical study on copper's energetics and magnetism in $\mathrm{TiO}_{2}$ polymorphs. J. Appl. Phys. 2013, 113, 233913.

(48) Okamoto, S.; Millis, A. J.; Spaldin, N. A. Lattice Relaxation in Oxide Heterostructures: $\mathrm{LaTiO}_{3} / \mathrm{SrTiO}_{3}$ Superlattices. Phys. Rev. Lett. 2006, 97, 056802. 
(49) Piyanzina I. I.; Kopp, T.; Yu, V. L.; Tayurskii, D. A.; Eyert, V. Electronic properties of $\mathrm{LaAlO}_{3} / \mathrm{SrTiO}_{3}$ n-type interfaces: a GGA+ U study. J. Phys. Condens. Matter 2017, 29, 095501.

(50) Gopal, P.; Spaldin, N. A. Magnetic interactions in transition-metal-doped $\mathrm{ZnO}$ : An ab initio study. Phys. Rev. B 2006, 74, 094418.

(51) Janotti, A.; Varley, J. B.; Rinke, P.; Umezawa, N.; Kresse, G.; Van de Walle, C. G. Hybrid functional studies of the oxygen vacancy in $\mathrm{TiO}_{2}$. Phys. Rev. B 2010, 81, 085212.

(52) Assadi, M. H. N.; Katayama-Yoshida, H. Dopant incorporation site in sodium cobaltate's host lattice: a critical factor for thermoelectric performance. J. Phys. Condens. Matter 2015, 27, 175504.

(53) Janotti, A.; Jalan, B.; Stemmer, S.; Van de Walle, C. G. Effects of doping on the lattice parameter of $\mathrm{SrTiO}_{3}$. Appl. Phys. Lett. 2012, 100, 262104.

(54) Toby, B.H. R factors in Rietveld analysis: How good is good enough? Powder Diffraction 2006, 21, 67-70.

(55) Campbell, C. T.; Daube, K. A. A Surface Science Investigation of the Water-Gas Shift Reaction on $\mathrm{Cu}(111)$. J. Catal. 1987, 104 (1), 109-119.

(56) Ginés, M. J. L.; Amadeo, N.; Laborde, M.; Apesteguía, C. R. Activity and StructureSensitivity of the Water-Gas Shift Reaction over Cu-Zn-Al Mixed Oxide Catalysts. Appl. Catal. A, Gen. 1995, 131 (2), 283-296.

(57) Ayastuy, J. L.; Gutiérrez-Ortiz, M. A.; González-Marcos, J. A.; Aranzabal, A.; González-Velasco, J. R. Kinetics of the LowTemperature WGS Reaction over a $\mathrm{CuO} / \mathrm{ZnO} / \mathrm{Al}_{2} \mathrm{O}_{3}$ Catalyst. Ind. Eng. Chem. Res. 2005, 44 (1), 41-50.

(58) Zhang, Y.; Chen, C.; Lin, X.; Li, D.; Chen, $\mathrm{X}$; Zhan, Y.; Zheng, Q. $\mathrm{CuO} / \mathrm{ZrO}_{2}$ Catalysts for Water-Gas Shift Reaction: Nature of Catalytically Active Copper Species. Int. J. Hydrogen Energy 2014, 39 (8), 3746-3754.
(59) Li, D.; Xu, S.; Cai, Y.; Chen, C.; Zhan, Y.; Jiang, L. Characterization and Catalytic Performance of $\mathrm{Cu} / \mathrm{ZnO} / \mathrm{Al}_{2} \mathrm{O}_{3}$ Water-Gas Shift Catalysts Derived from $\mathrm{Cu}-\mathrm{Zn}-\mathrm{Al}$ Layered Double Hydroxides. Ind. Eng. Chem. Res. 2017, 56 (12), 3175-3183.

(60) Hutchings, G. J.; Copperthwaitet, R. G.; Gottschalk, F. M.; Hunter, R.; Mellor, J.; Orchard, S. W.; Sangiorgio, T. A Comparative Evaluation of Cobalt Chromium Oxide, Cobalt Manganese Oxide, and Copper Manganese Oxide as Catalysts for the Water-Gas Shift Reaction. $J$. Catal. 1992, 137 (2), 408-422.

(61) Keiski, R. L.; Desponds, O.; Chang, Y. F.; Somorjai, G. A. Kinetics of the Water-Gas Shift Reaction over Several Alkane Activation and Water-Gas Shift Catalysts. Appl. Catal. A, Gen. 1993, 101 (2), 317-338.

(62) Li, Y.; Fu, Q.; Flytzani-Stephanopoulos, M. Low-Temperature Water-Gas Shift Reaction over $\mathrm{Cu}$ - and Ni-Loaded Cerium Oxide Catalysts. Appl. Catal. B Environ. 2000, 27 (3), 179-191.

(63) Koryabkina, N. A.; Phatak, A. A.; Ruettinger, W. F.; Farrauto, R. J.; Ribeiro, F. H. Determination of Kinetic Parameters for the Water-Gas Shift Reaction on Copper Catalysts under Realistic Conditions for Fuel Cell Applications. J. Catal. 2003, 217 (1), 233-239.

(64) Choi, Y.; Stenger, H. G. Water Gas Shift Reaction Kinetics and Reactor Modeling for Fuel Cell Grade Hydrogen. J. Power Sources 2003, 124 (2), 432-439.

(65) Rodriguez, J. A.; Liu, P.; Hrbek, J.; Evans, J.; Pérez, M. Water Gas Shift Reaction on $\mathrm{Cu}$ and $\mathrm{Au}$ Nanoparticles Supported on $\mathrm{CeO}_{2}(111)$ and $\mathrm{ZnO}(000)$ : Intrinsic Activity and Importance of Support Interactions. Angew. Chemie 2007, 119 (8), 1351-1354.

(66) Jang, W. J.; Roh, H. S.; Jeong, D. W. An Important Factor for the Water Gas Shift Reaction Activity of Cu-Loaded Cubic $\mathrm{Ce}_{0.8} \mathrm{Zr}_{0.2} \mathrm{O}_{2}$ Catalysts. Environ. Eng. Res. 2018, 23 (3), 339-344.

(67) Xia, S.; Fang, L.; Meng, Y.; Zhang, X.; Zhang, L.; Yang, C.; Ni, Z. Water-Gas Shift 
Coletta, Vitor C., et al. "Cu-Modified SrTiO3 Perovskites Toward Enhanced Water-Gas Shift Catalysis: A Combined Experimental and Computational Study." ACS Applied Energy Materials (2021), 4, 1, 452-461

Reaction Catalyzed by Layered Double Hydroxides Supported Au-Ni/Cu/Pt Bimetallic Alloys. Appl. Catal. B Environ. 2020, 272 (March), 118949.

(68) Nakamura, J.; Campbell, J. M.; Campbell, C. T. Kinetics and Mechanism of the Water-Gas Shift Reaction Catalysed by the Clean and CsPromoted $\mathrm{Cu}(110)$ Surface: A Comparison with $\mathrm{Cu}(111)$. J. Chem. Soc. Faraday Trans. 1990, 86 (15), 2725-2734.

(69) Rodriguez, J.; Liu, P.; Wang, X.; Wen, W.; Hanson, J.; Hrbek, J.; Pérez, M.; Evans, J. Watergas shift activity of $\mathrm{Cu}$ surfaces and $\mathrm{Cu}$ nanoparticles supported on metal oxides. Catal. Today 2009, 143, 45-50.

(70) Kubacka, A.; Fernández-García, M.; Martínez-Arias, A. Catalytic hydrogen production through WGS or steam reforming of alcohols over $\mathrm{Cu}, \mathrm{Ni}$ and Co catalysts. Appl.

Catal. A 2016, 518, 2-17.

(71) Grinchuk, P. S.; Rabinovich, O. S. Extremum of the percolation cluster surface. $J$. Exp. Theor. Phys. 2003, 96, 301-309.

(72) Nguyen, M. H.; Lee, S.-J.; Kriven, W. M. Synthesis of oxide powders by way of a polymeric steric entrapment precursor route. $J$. Mater. Res. 2011, 14, 3417-3426.

(73) Carlotto, S.; Vittadini, A.; Casarin, M. DFT modelling of the $\mathrm{CO}-\mathrm{NO}$ redox reaction at $\mathrm{Cu}-$ doped $\mathrm{SrTiO}_{3}(100)$ stepped surface: $\mathrm{CO}$ oxidation at lattice O ions. Inorg. Chim. Acta, 2020, 511, 119810.

(74) Carlotto, S.; Glisenti, A; Vittadini, A.; Casarin, M. Adsorption and reactivity of $\mathrm{CO}$ at a stepped $\mathrm{SrTiO}_{3}(100)$ surface in the presence of $\mathrm{Cu}$ impurities. Appl. Surf. Sci. 2020, 521, 146450.

(75) Yun, J.-N.; Zhang, Z.-Y, Yan, J.-F.; Zhang, F.-C. First-Principles Study of Adsorption and Reaction of $\mathrm{CO}$ on $\mathrm{SrTiO}_{3}$ (100) Surface: the Role of Surface Oxygen Vacancies. Chin. Phys. Lett. 2010, 27, 017101.

(76) Föhlisch, A.; Nyberg, M.; Hasselström, J.; Karis, O.; Pettersson, L.; Nilsson, A. How carbon monoxide adsorbs in different sites. Phys. Rev. Lett. 2000, 85, 3309.

(77) Gamel, K. M.; Sharafeldin, I. M.; Abourayya, A. U.; Biby, A. H.; Allam, N. K. Unveiling $\mathrm{CO}$ adsorption on $\mathrm{Cu}$ surfaces: new insights from molecular orbital principles. Phys. Chem. Chem. Phys. 2018, 20, 25892-25900.

(78) Manthey, W. Orbital Viewer. http://www.orbitals.com/orb/, accessed on 23/11/2020. 